\title{
Biocompatibility, biodegradation and biomedical applications of poly(lactic acid)/poly(lactic-co-glycolic acid) micro and nanoparticles
}

\author{
Enas M. Elmowafy ${ }^{1} \cdot$ Mattia Tiboni $^{2} \cdot$ Mahmoud E. Soliman $^{1}$
}

Received: 7 February 2019 / Accepted: 4 April 2019 / Published online: 16 April 2019

(C) The Korean Society of Pharmaceutical Sciences and Technology 2019

\begin{abstract}
Background Poly(lactic acid) (PLA) and poly(lactic-co-glycolic acid) (PLGA) are among the well-documented FDAapproved polymers used for the preparation of safe and effective vaccine, drug and gene delivery systems using well-described reproducible methods of fabrication. Various nano and microparticulates are fabricated using these polymers. Their successful performance relies on PLA and PLGA biocompatibility and degradability characteristics.

Area covered This review provides an overview of the biocompatibility and biodegradation of PLA, PLGA and their copolymers, with a special emphasis on tissue responses for these polymers as well as their degradation pathways and drug release models. Moreover, the potential of PLA and PLGA based nano and microparticulates in various advanced biomedical applications is highlighted.

Expert opinion PLA and PLGA based delivery systems show promises of releasing different drugs, proteins and nucleic acids in a stable and controlled manner and greatly ameliorating their therapeutic efficacy. In addition, advancement in surface modification and targeting of nanoparticles has extended the scope of their utility.
\end{abstract}

Keywords Biocompatibility $\cdot$ Biodegradation $\cdot$ PLA $\cdot$ PLGA $\cdot$ Microparticles $\cdot$ Nanoparticles

\section{Introduction}

Extensive studies have shown the importance of using biocompatible and biodegradable polymers for drug delivery applications (Hughes 2017). Broadly speaking, many natural, viz., polysaccharides and proteins, and synthetic, viz. poly $(\alpha$-hydroxy esters) polymers play a pivotal role in this respect, by virtue of their biocompatibility and biodegradability. However, the use of natural polymers in certain delivery applications can be disadvantageous from degradation perspective, exhibiting heightened, uncontrolled and inconsistent degradation (Abedalwafa et al. 2013). In contrast,

Enas M. Elmowafy

enasmostafa@pharma.asu.edu.eg

1 Department of Pharmaceutics and Industrial Pharmacy, Faculty of Pharmacy, Ain Shams University, Monazzamet Elwehda Elafrikeya Street, Abbaseyya, P.O. 11566, Cairo, Egypt

2 Department of Biomolecular Sciences, School of Pharmacy, University of Urbino, Piazza Rinascimento, 6, 61029 Urbino, PU, Italy uniqueness of synthetic polymers lies in the feasibility to tailor their chemical, physical and mechanical features, controlling their degradation rate (Dhandayuthapani et al. 2011; Gentile et al. 2014).

Specifically, synthetic polyesters show great promises, including polymers such as Poly-epsiloncaprolactone (PCL), poly(glycolic acid) (PGA),poly(lactic acid) (PLA) and poly(lactic-co-glycolic acid) (PLGA). By comparison with other polyesters, PCL degradation is exclusively very slow, limiting its utilization in some specific biomedical fields and necessitating its modification such as surface decoration or forming composite systems with other natural and synthetic polymers (Abedalwafa et al. 2013). PGA, on the other hand, exhibited faster degradation rate despite its structural similarity with PLA, and hence, this polymer cannot meet up with the requirements of advanced delivery systems (Gentile et al. 2014; Vroman and Tighzert 2009).

In the family of polyesters, PLA and PLGA, also known as polylactide and polylactide-co-glycolide respectively, have been the most used for drug delivery applications, owing to their attractive mechanical and processing characteristics (Martins et al. 2018; Reis et al. 2017). In addition, 
contrary to others biodegradable polyesters which are synthesized from petrochemical sources such as polyhydroxyalkanoates (PHA) and poly(butylene succinate) (PBS), PLA and PLGA polymers are produced by lactic and glycolic acid fermentation from sugars which make them more green and eco-friendly (Dischert and Soucaille 2015; Juturu and Wu 2016; Koivistoinen et al. 2013).

Several systems based on PLA or PLGA have been prepared to deliver different payloads ranging from small drug molecules to large proteins and nucleic acids in a sustained release manner (Sun et al. 2014). The rate of drug release and cellular uptake from such systems could be easily tunable by changing several factors such as particle size, polymer crystallinity, polymer molecular weight $\left(\mathrm{M}_{\mathrm{wt}}\right)$, polymer chemical composition, drug loading and drug-polymer interaction (Kamaly et al. 2016).

Being biocompatible, PLA and PLGA produce safe and non-toxic degradation products which made them good candidates for many medical and pharmaceutical applications (Alsaheb et al. 2015). The biodegradation of PLA and PLGA-based homo and copolymers involve their hydrolytic degradation to lactic and glycolic acids which are finally eliminated from the body as $\mathrm{CO}_{2}$ and water (Tačić et al. 2017). The biodegradation of PLA and PLGA based drug delivery systems (DDS) is very important with regard to controlling the release of loaded cargos (Kamaly et al. 2016). As the polymer degrades and erodes, the drug release kinetics is a function of polymer degradation as well as drug diffusion through polymer matrix (Xu et al. 2017).

Various microparticles (MPs) and nanoparticles (NPs) can be designed using FDA-approved biodegradable and biocompatible PLA and PLGA. These particulate systems possess excellent biocompatibility, controllable biodegradability and erosion and high safety profiles (Agrahari et al. 2016). Therapeutic agents and biologics can be encapsulated within such polymeric particulates for localized and systemic delivery (Yan et al. 2012). Many multifaceted merits are realized in PLA and PLGA based DDS such as sustainment of drug release, targeted delivery, improving the bioavailability, and enhancement of the stability of encapsulated biopharmaceuticals towards enzymatic degradation (Moghimi et al. 2001; Mundargi et al. 2008). With great effort, in the last years, different PLA and PLGA based drugs delivery systems have been developed, in particular for the delivery of anticancer drugs (Haggag et al. 2019; Jain et al. 2011, 2016; Shao et al. 2018) and for a specific organ targeting such as brain or liver targeting (Bao et al. 2015; Gao et al. 2015; Jose et al. 2014; Patel et al. 2018; Xia et al. 2012; Zhu et al. 2016). Moreover, these delivery systems have been tested with great results for pulmonary administration of different drugs (Feng et al. 2014; Gaspar et al. 2019; Takami and Murakami 2011). Furthermore, therapeutic gene delivery based on these systems has been explored especially loading pDNA, mRNA, siRNA and microRNA (Gomes dos Reis et al. 2019; Matta and Maalouf 2019; Nishio et al. 2018; Terry et al. 2019; Xu et al. 2018; Zhao et al. 2018).

We aim in this manuscript to briefly review the most popular biodegradable polymers, PLA and PLGA, as well as micro- and nanoparticle systems with regard to their biocompatibility and biodegradation and their impact as delivery systems for vaccines, drugs and genes with optimal efficacy.

\section{Poly (lactic acid) (PLA) and poly (lactic-co-glycolic acid) (PLGA)}

PLA and PLGA are among the most highly studied polymers used in medical applications for drug delivery (Brown et al. 2015; Ramot et al. 2016). PLA present asymmetric centers in its backbone resulting in the formation of either $\mathrm{D}$ or $\mathrm{L}$ forms (PDLA or PLLA), while PLGA is the copolymer of D,L-lactic acid with glycolic acid (Silva et al. 2015). Figure 1 depicts the chemical structures of PLA and PLGA polymers. It is worth to say that PLLA acquires crystalline form while PDLA with disordered polymer chains is amorphous (Müller et al. 2013). Moreover, the absence of side chain in case of glycolic acid in PLGA enhance chain packing and hence polymer crystallinity when compared to PLLA of similar molecular weight (Tesfamariam 2016).

PLA and PLGA are easily shaped to DDS of various architectures, being soluble in many solvents including chloroform, dichloromethane, tetrahydrofuran (THF), acetone and ethyl acetate (Mohammadi-Samani and Taghipour 2015). They are insoluble in water; however, they absorb water and degrade by hydrolysis of their ester linkage. The
Fig. 1 Chemical structure of $\mathbf{A}$ PLA and B PLGA
A

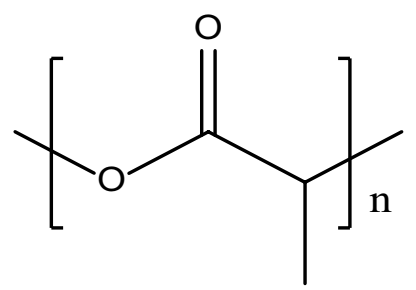

B

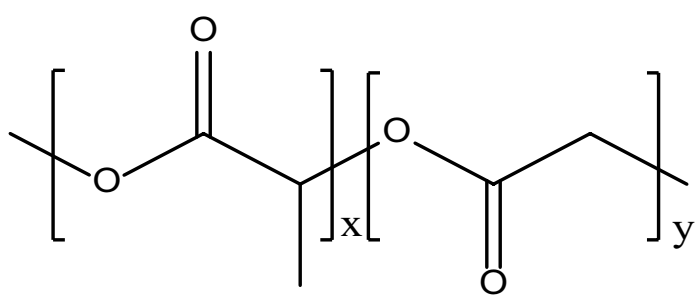


hydrophobic side chain (methyl groups) of PLA renders the polymer with lower water uptake properties and slower degradation compared to PLGA (Fig. 1). Therefore, the drug release from PLGA would be much faster than that from PLA (Makadia and Siegel 2011). Many polymeric DDS, including MPs and NPs, were developed using PLA, PLGA and their copolymers for delivering various drugs (Kapoor et al. 2015; Mohammadi-Samani and Taghipour 2015; Tyler et al. 2016).

\section{Biocompatibility of PLA and PLGA}

The biocompatibility of PLA and PLGA was tested and proofed both in vitro and in vivo (Mir et al. 2017). The ultimate biocompatibility of polymers is influenced, not only by polymers but also by their nature of degradation products and degradation rate (Engineer et al. 2011). As mentioned above, PLA and PLGA polymers degrade by esterase enzyme, forming lactic and glycolic acids that enter Kreb`s cycle to be eliminated as $\mathrm{CO}_{2}$ and water through respiration, feces, and urine (Silva et al. 2015). Accumulation of these polymers, when used in low concentration, in the human body organs has never been reported. Nevertheless, in some cases due to failure on the elimination of degradation byproducts, the in situ accumulation of acidic (lactic and glycolic acids) degradation products become dangerous, altering biological response when in contact with tissues at high local concentrations (Ramot et al. 2016).

Also, the release of small non-degraded fragments and particulates during polymer erosion process could activate different unexpected immune responses by macrophages (Lyu and Untereker 2009). Moreover, particulates type of PLA and PLGA based systems is of prime importance, when considering toxicological issues. Due to their enhanced cellular uptake and biodistribution, NPs might have affected cell growth, viability and tissue responses (Dailey et al.
2006; Makadia and Siegel 2011). Thus, investigation of particles safety profile, on a cellular or tissue level is highly warranted.

Although larger polymeric microparticles cannot be taken up by macrophages (Champion et al. 2008; Gustafson et al. 2015), macrophages in proximity to polymer surface secretes polymer damaging agents that help MPs erosion process and help starting phagocytosis process (Ronneberger et al. 1996). Furthermore, the interior of macrophage lysosomal vesicles has highly acidic $\mathrm{pH}(\sim 3)$ (Galloway et al. 1983), compared to the extracellular environment, that can accelerate the process of PLA and PLGA degradation (Zhou and Deng 2002).

It is worthy to mention that biocompatibility is not only the polymer's intrinsic property-dependent or particulate type-dependent, but also, biological environment-dependent and hence, intensity and length of specific polymer-tissue interactions can be varied greatly in different organs, tissues and species (Makadia and Siegel 2011; Ramot et al. 2016, 2015). Thus, site of administration of PLA and PLGA based DDS greatly impacted foreign body responses. The prolonged tissues/particulates interface and their continual presence inside the tissues can elicit intolerable inflammation, injury and immunological rejection (Ramot et al. 2016). For example, implantation of PLA and PLGA based DDS, with a high surface area and low injection volume via subcutaneous (SC) or intramuscular (IM) routes may increase the risk of a persistent local foreign body reaction over the duration time of polymer degradation.

PLA and PLGA local tissue responses involve three steps: (i) Organization of the inflammatory responses; (ii) Monocytes migration to DDS injection site which differentiate into macrophages and fibrous capsule development; (iii) Rapid degradation of the polymer and enhanced formation of fibrous tissues generated in second step (KyungáKim 2016). A diagrammatic illustration of tissue response steps to PLA and PLGA DDS is presented in Fig. 2.
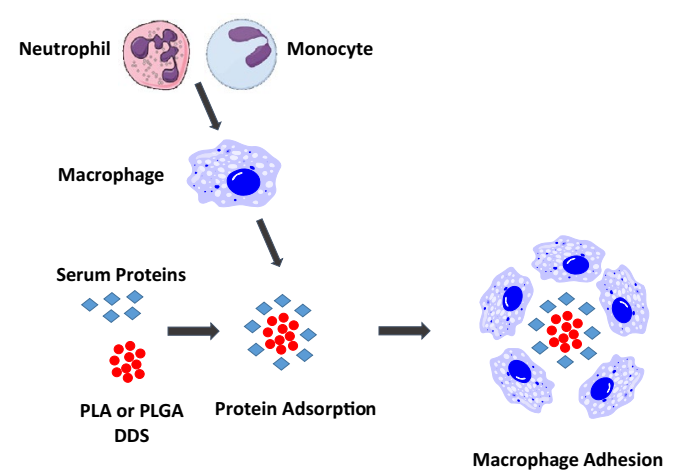
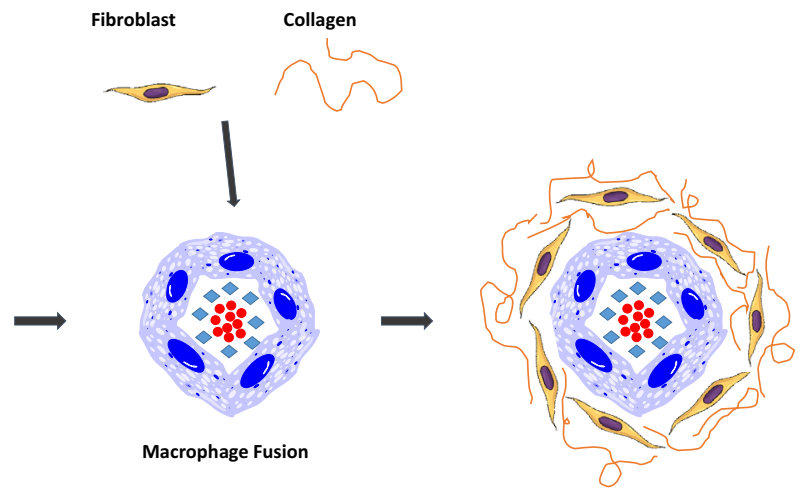

Fibrous Encapsulation 
Specifically, recognition of the intravenous (IV) NPs by the reticuloendothelial system (RES) is heightened, resulting in their phagocytosis. However, the rationale design of functional long-circulating PLGA NPs via surface modification with hydrophilic polymers such as polyethylene glycol (PEG), poloxamers and polysaccharides greatly stabilizes NPs against opsonization (Gref et al. 2000; Mahapatro and Singh 2011; Yoo et al. 2010). Interestingly, the alleviating influence of incorporated therapeutic agents insides PLA and PLGA DDS must be considered as such tissue responses can be greatly diminished due to drug encapsulation (Ramot et al. 2016). For instance, loading PLGA MPs with antiinflammatory drugs such as dexamethasone has been demonstrated to provide long term control over inflammation and fibrosis, improving their performance following SC implantation (Bhardwaj et al. 2010; Dang et al. 2011).

Concerning utilization of PLA and PLGA based DDS to other administration sites such as intravitreal, intraparenchymal "for brain delivery", intratracheal and intracochlear implantations, previous studies evidenced that they meet the biocompatibility requirements. Mild tissue responses have been shown, if any with the absence of histological alterations or cell ultrastructure modification (Ensari et al. 2015; Kim et al. 2011; Lewitus et al. 2011; Rong et al. 2014).

\section{Biodegradation of PLA and PLGA}

PLA and PLGA belong to the large family of biodegradable aliphatic polyesters (Vroman and Tighzert 2009). PLA and PLGA polymers, prepared with different isomer composition and polymer molecular weight, have variable melting points and crystallinity (Ahmed and Varshney 2011). Moreover, the biodegradation of these polymers in the human body can be controlled (i.e. retarded) by the incorporation of D-lactide isomer in their backbones. The fact that our bodies do not produce enzymes that can utilize D-lactic acid results in reduced degradability of polymers containing D-lactide monomer (Gorrasi and Pantani 2013).

The biodegradation of polyesters including PLA and PLGA mainly occurs by hydrolytic degradation which may be enzyme catalyzed (Elsawy et al. 2017). Several factors can affect hydrolytic degradation process including (i) water permeability and solubility, (ii) chemical composition and molecular weight and molecular weight distribution, (iii) the mechanism of hydrolysis (noncatalytic, autocatalytic, enzymatic), (iv) additives (acidic, basic, monomers, solvents, drugs), (v) polymer crystallinity, (vi) glass transition temperature (glassy, rubbery) and other physicochemical factors (e.g. ionic strength, pH) (Antheunis et al. 2009; Frank et al. 2005; Makadia and Siegel 2011; Xu et al. 2017; Zolnik and Burgess 2007).
The most important factor affecting the degradation of PLA and PLGA and particles prepared by them is polymer molecular weight (Anderson and Shive 1997) and degree of crystallization (Mitchell and Hirt 2015). Crystalline parts of the polymer show more resistance to degradation when compared to amorphous regions (Göpferich 1996). The crystallinity of the polymer depends on its composition i.e. increasing the percentage of glycolide monomer in PLGA backbones decreases polymer crystallinity as it decreases chain rearrangement to produce crystalline structures (Keles et al. 2015; Xu et al. 2017).Moreover, it was found that increasing PLA and PLGA molecular weights, their degradation rate decreases because of the high chain-chain crossing between long polymer backbones which lead to the resistance of chain cleavage (Makadia and Siegel 2011).

The extent of water uptake affects the hydrolytic degradation of PLA and PLGA as water reacts with polyesters, resulting in reverse polycondensation (Alexis 2005). Various factors affect water uptake of these polymers including; molecular weight, purity, morphology, and the polymer processing techniques (Antheunis et al. 2010; Dorati et al. 2007; Keles et al. 2015). The abundance of water is critical to start ester bond degradation to oligomers and monomers, especially for high molecular weight polymers. Furthermore, polymer porosity helps in increasing polymer biodegradation by increasing water uptake as well as cellular migration through polymer macropores (Rodriguez et al. 2016).

PLA and PLGA degradation was found to increase in acidic (Zolnik and Burgess 2007) and basic (Wang et al. 1998) conditions, hence, the incorporation of large amounts of acid and basic drugs (D'Souza et al. 2015) and/or additives (Yoo et al. 2005) to them enhances degradation kinetics. It is also worth to note that phagolysosomal vacuoles of macrophages have acidic content $(\mathrm{pH} \sim 3$ ) which, when secreted on the interface with the polymers, facilitate their biodegradation (Anderson and Shive 1997).

\section{Methods used for the characterization of polymer degradation}

Many techniques have been used to investigate the process of PLA and PLGA degradation through tracking the physical or chemical changes that happen during polymer breakdown to oligomers and monomers (Engineer et al. 2011; Keles et al. 2015). Figure 3 shows different techniques used to probe polymers degradation. The different techniques usually involve either direct investigation of the variations in polymer molecular weight with time (e.g. gel permeation chromatography (GPC) (Bawa et al. 2018) and timeof-Flight secondary ion mass spectrometry (TOF-SIMS) (Marchany et al. 2015)) or testing the changes in different physical properties which are correlated to polymer size (e.g. 


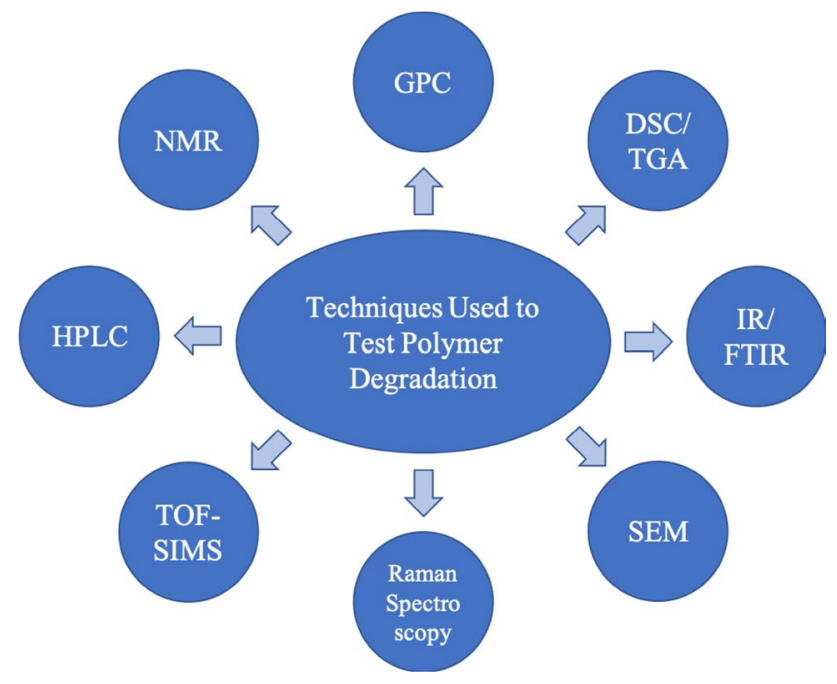

Fig. 3 Different techniques used to probe degradation of polymers

crystallinity and thermal properties i.e. differential scanning calorimetry (DSC) and thermo gravimetric analysis (TGA)) (Turek et al. 2015). Moreover, degradation can be assessed by tracing properties of the polymer such as loss of molecular mass which can be demonstrated using GPC and changing of polymer crystallinity which can be assessed by studying changes in its thermal properties.

Other techniques involve following the buildup of monomer molecules during degradation and this could be followed using $\mathrm{pH}$ changes for acidic and basic monomers, high performance liquid chromatography (HPLC) (Giunchedi et al. 1998), Fourier transform infrared spectroscopy (FTIR) (Leroy et al. 2017), nuclear magnetic resonance (NMR) and Raman spectroscopy (Kasyapi et al. 2015). Qualitative methods by imaging polymer using scanning electron microscopy (SEM) (Liu et al. 2006) and atomic force microscopy (AFM) (Giannouli et al. 2018) have been used to check polymer degradation by probing morphological changes with time.

\section{Degradation pathways and drug release models}

The degradation of PLA and its copolymers occur by three hydrolytic pathways: (i) surface degradation, (ii) bulk degradation and (iii) bulk degradation with autocatalysis (Gajjar and King 2014) (Fig. 4). For the surface degradation or erosion, the cleavage of ester bonds of polymers occurs mainly on the surface, resulting in the formation of monomers and oligomers that diffuse to the degradation medium faster than those produced in the polymer bulk. Bulk erosion happens when degradation medium penetrates polymer matrix and random hydrolysis occurs throughout the polymer bulk, reducing its backbone molecular weight. During the gradual bulk erosion

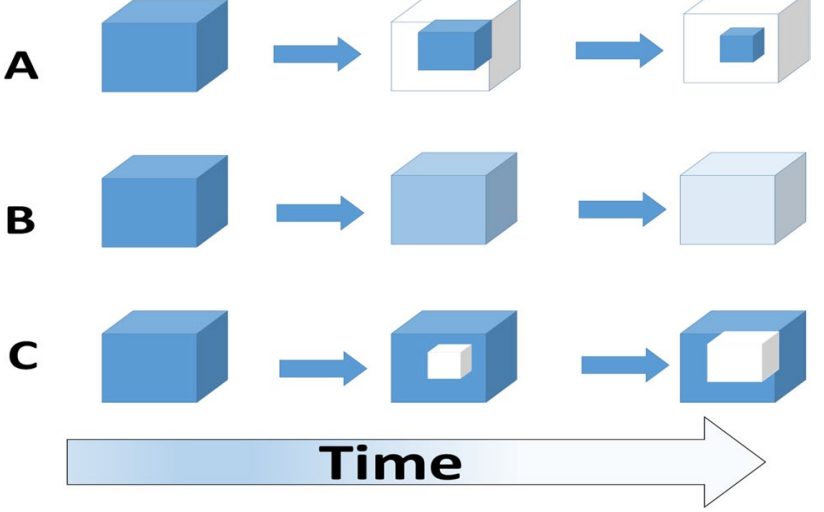

Fig. 4 Degradation pathways for PLA and its copolymers: A surface degradation, $\mathbf{B}$ bulk degradation, $\mathbf{C}$ bulk degradation with autocatalysis

process, as long as the degradation medium diffuses throughout the hydrolyzing matrix, monomers and oligomers diffuse to the degradation medium and the polymer density decrease (von Burkersroda et al. 2002). When the bulk degradation results in the formation of a higher concentration of acidic degradation products in the polymer interior compared to the polymer surface, autocatalysis may happen, accelerating the internal degradation. As the polymer interior degradation increases, monomers and oligomers diffuse rapidly, producing polymer matrix with hollowed core (Antheunis et al. 2010).

PLA and PLGA degrade with second order (2nd) order kinetics depending on both ester bond and water concentration (Lyu and Untereker 2009). As hydrolysis or autocatalysis proceeds, the number average molecular weight $\left(M_{n}\right)$ of polymers decreases with the increase in chain end concentration (CE) and this could be quantified by the following equation:

$C E=\frac{X}{V}=\frac{\rho}{M n}=\frac{\rho}{N \cdot M_{0}}$

where $\mathrm{X}, \mathrm{V}$, and $\rho$ : total number of chains, volume, and density of the samples; $\mathrm{N}$ : degree of polymerization; $\mathrm{M}_{0}$ : monomer molecular weight.2nd order hydrolysis reaction can be described as follows:

$\frac{d C E}{d t}=k_{2} C_{e} C_{w}$

where $\mathrm{k}_{2}$ : rate constant; $\mathrm{C}_{\mathrm{e}}$ : ester bond concentration; $\mathrm{C}_{\mathrm{w}}$ : water concentration.

By combining Eqs. $(1,2)$, the number average molecular weight $\left(\mathrm{M}_{\mathrm{n}}\right)$ can be calculated from 2 nd order hydrolysis equation:

$\frac{1}{M n}=\frac{1}{M n_{0}}+\frac{1}{M_{0}} k_{2} C_{e} t$ 
where $\mathrm{M}_{\mathrm{n}}$ : number average molecular weight at time $\mathrm{t} ; \mathrm{M}_{\mathrm{n} 0}$ : initial number average molecular weight before starting hydrolysis reaction. In the case of auto-accelerated degradation or autocatalysis, the degradation rate is proportional to the chain bond concentration as well as water and hydrolytic bond concentrations as follows:

$\log M n=\log M n_{0}-k_{3} C_{e} C_{w} t$

where $\mathrm{k}_{3}$ : autocatalysis rate constant.

The release of different drugs from PLA or PLGA matrix is the sum of surface and bulk diffusion as well as matrix erosion mechanisms (Makadia and Siegel 2011). The drug release occurs mainly by diffusion when the polymer weight loss is minimal. This could be described by the following equation:

$\frac{\partial C(r, t)}{\partial t}=\frac{1}{r^{2}} \frac{\partial}{\partial r}\left(r^{2} D\left(M_{w}\right) \frac{\partial C(r, t)}{\partial r}\right)$

where C: drug concentration; r: radial position; t: time; $\mathrm{D}\left(\mathrm{M}_{\mathrm{w}}\right)$ : polymer molecular weight dependent diffusivity of the drug.

When polymers are formulated into MPs or NPs, the effect of population size distribution on drug release can be described by the following equation:

$\frac{1}{M_{\infty}} \frac{\partial M_{\text {drug }}}{\partial r}=f(r ; \lambda, k)=\frac{k}{\lambda}\left(\frac{r}{\lambda}\right)^{k-1} \exp \left(-\left(\frac{r}{\lambda}\right)^{k}\right)$

where $M_{\infty}$ : drug total mass in the population; $M_{d r u g}$ : drug mass in one particle and $r$ is the particle radius.

\section{Biomedical applications of PLA and PLGA nano- and microsystems}

During the last decade, several research groups have prepared nano- and microsystems using PLA and PLGA for many therapeutic applications. They aimed to use these biodegradable and biocompatible polyesters to modify drug release and enhance its activity and optimal therapeutic effectiveness (Lee et al. 2016; Sharma et al. 2016). In the following sections, we will discuss part of extensive applications of the currently developed PLA and PLGA based nano and microsystems with emphasis on their beneficial effect in the delivery of biopharmaceuticals, viz., drugs, vaccines and gene delivery (Tables 1, 2 and 3). Examples of recent research studies in the last ten years which deal with biodegradation and biocompatibility of PLA and PLGA nano- and microparticulate delivery systems and their main achievements are covered in this review.

\section{PLA and PLGA based MPs and NPs delivery systems for vaccine delivery}

The potential of polyesters to produce delivery platforms adequate for vaccination for preventive and therapeutic purposes has been increasingly explored. Their attractiveness in protein and peptide delivery stemmed from their ability to act as safe and efficacious vaccines adjuvants and to coencapsulate antigens and/or immunomodulators and other vaccine adjuvants (Ahmed and Varshney 2011; Demento et al. 2012; Kasturi et al. 2011; Mundargi et al. 2008; Schlosser et al. 2008; Wischke et al. 2009). Antigen-containing polymeric particulates get due recognition of strong and long lasting T-lymphocytes responses as compared to the soluble antigens (Cruz et al. 2017). Other striking features include protection of their payload from proteolytic degradation, sustained antigen availability, peptide dosage reduction, minimized immunization times and reduced toxicity (Demento et al. 2012; Getts et al. 2014; Tam et al. 2016).

As a consequence, the coordination of more robust optimal humoral and cellular arms of the immune response, mimicking the natural infection influence, could be achieved (Demento et al. 2012; Kasturi et al. 2011). The mechanism behind such stimulatory capacity is the phagocytosis of the particles by dendritic cells (DCs), the most professional cellular target, leading to the maturation markers up-regulation (such as CD40 and CD80) and antibody and T-lymphocytes activation and proliferative response to different antigens (Anderson et al. 2008; Clawson et al. 2010; Danhier et al. 2012; Luzardo-Alvarez et al. 2005; Rosas et al. 2001; Waeckerle-Men and Groettrup 2005). Interestingly, anti-cancer immunotherapy could be realized by such immune system alerts, through their capability to encapsulate ligands for Toll-like receptors (TLRs) (Hamdy et al. 2011; Kranz et al. 2016; PinzonCharry et al. 2007; Seth et al. 2017; Zhang et al. 2011).

The utilization of particulate formulated vaccines with controlled size (preferentially in the micron range), charge, polymer composition, molecular weight, degradation rate and, hydrophobicity could guarantee non-specific long lasting DCs targeting (Feng et al. 2006; Kanchan and Panda 2007; Kazzaz et al. 2006). In particular, degradability governed the second phase of the mechanism behind the release of peptides/proteins, following the initial phase of diffusion, and hence, their immunization response and the proposed regimen (Taha et al. 2012). In addition, nature of co-adjuvants and delivery route play a critical role in the efficacy of these protective immunity generators (Ashhurst et al. 2018; Newman et al. 2002; Renukuntla et al. 2013). A selection of some examples on the application of PLA and PLGA based MPs and NPs delivery systems for vaccine delivery is reviewed in Table 1, with 


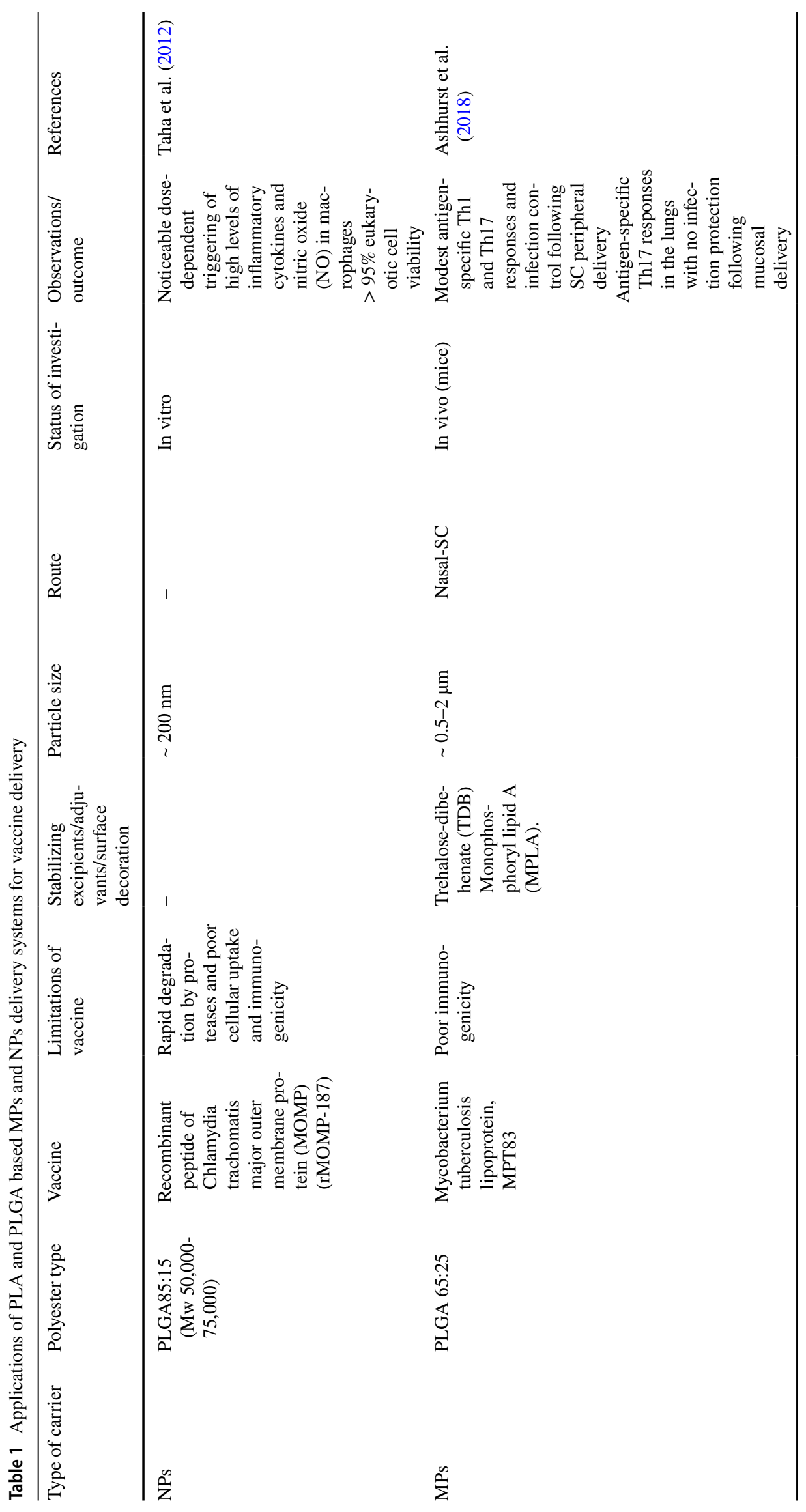




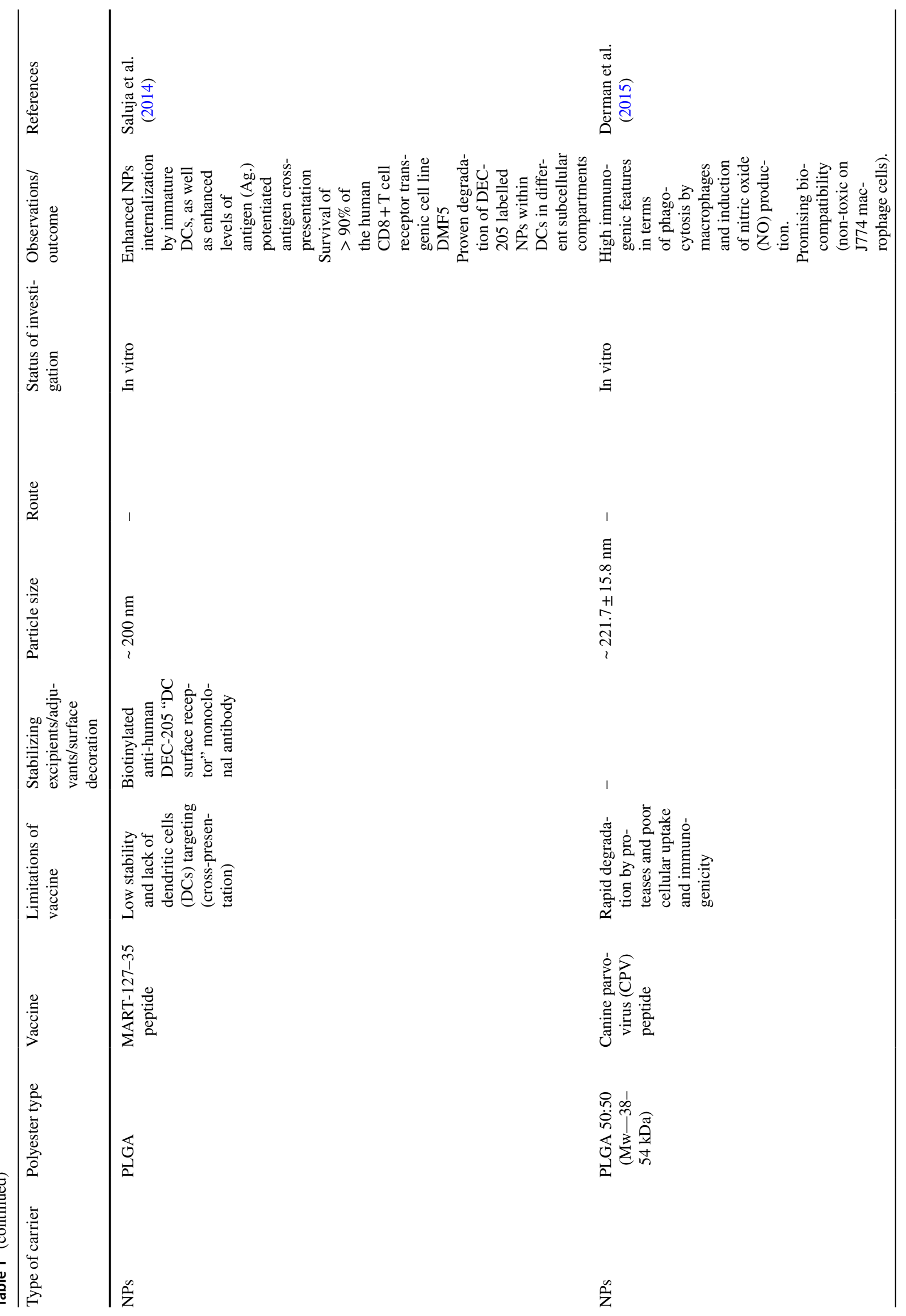




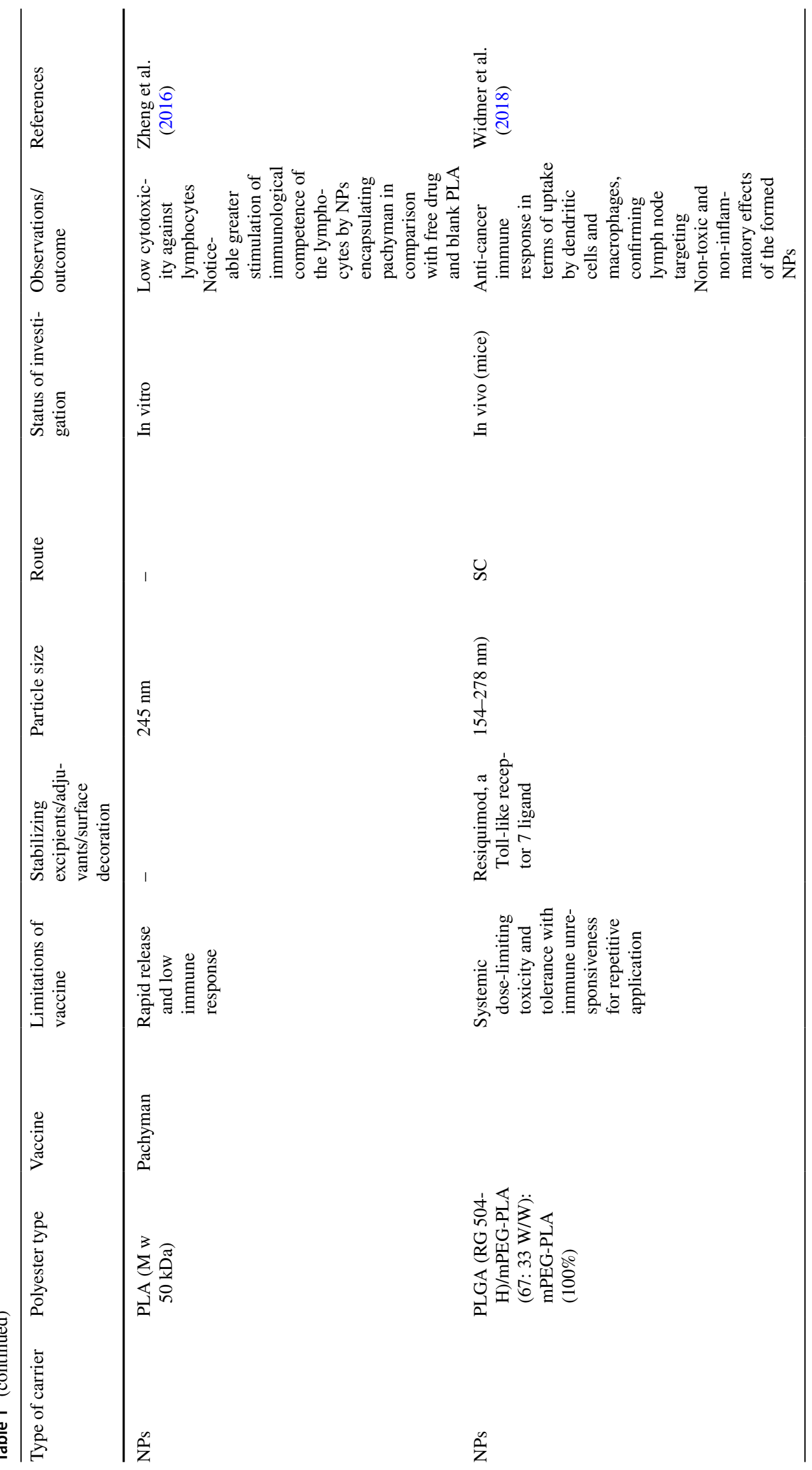




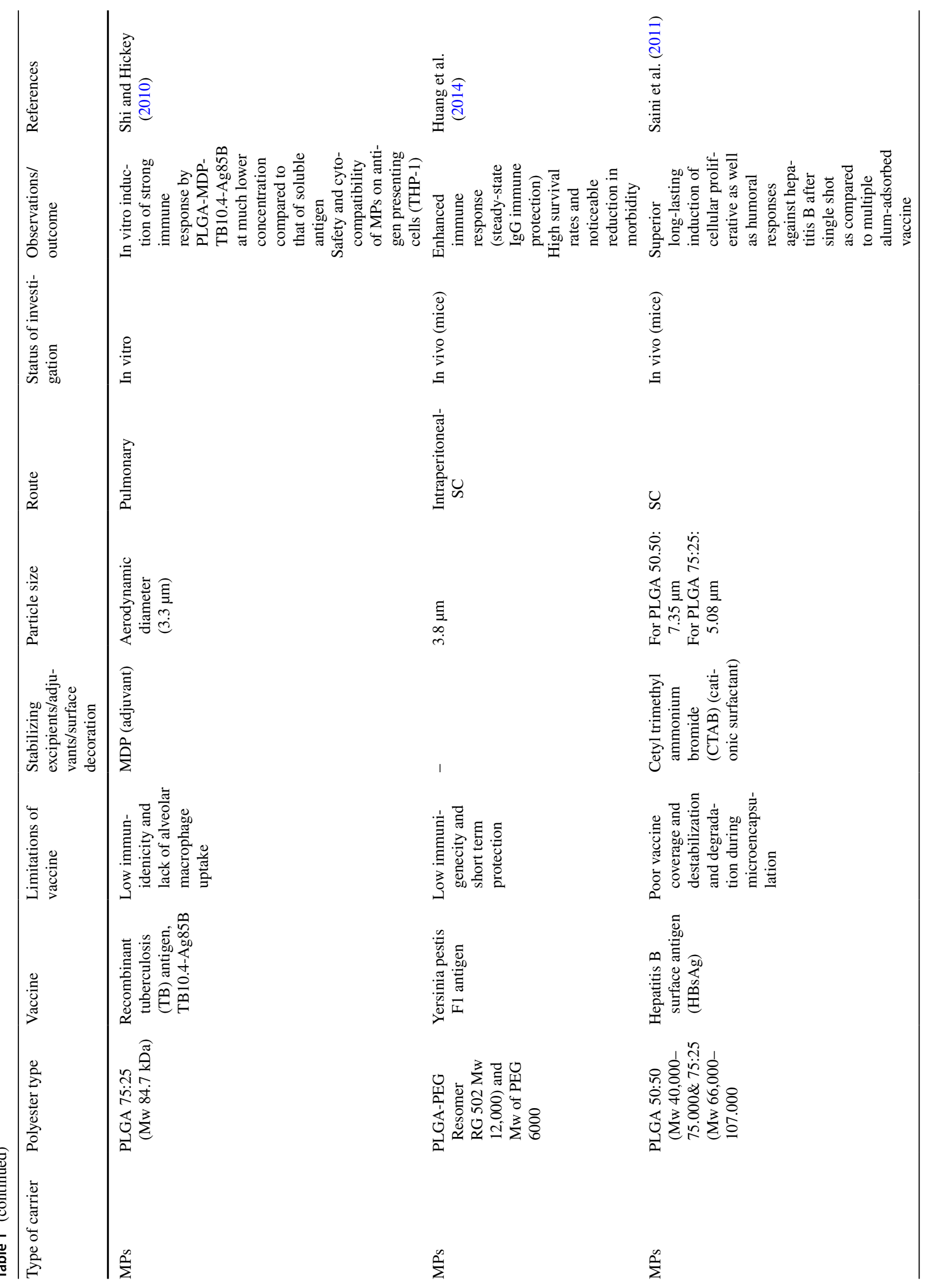




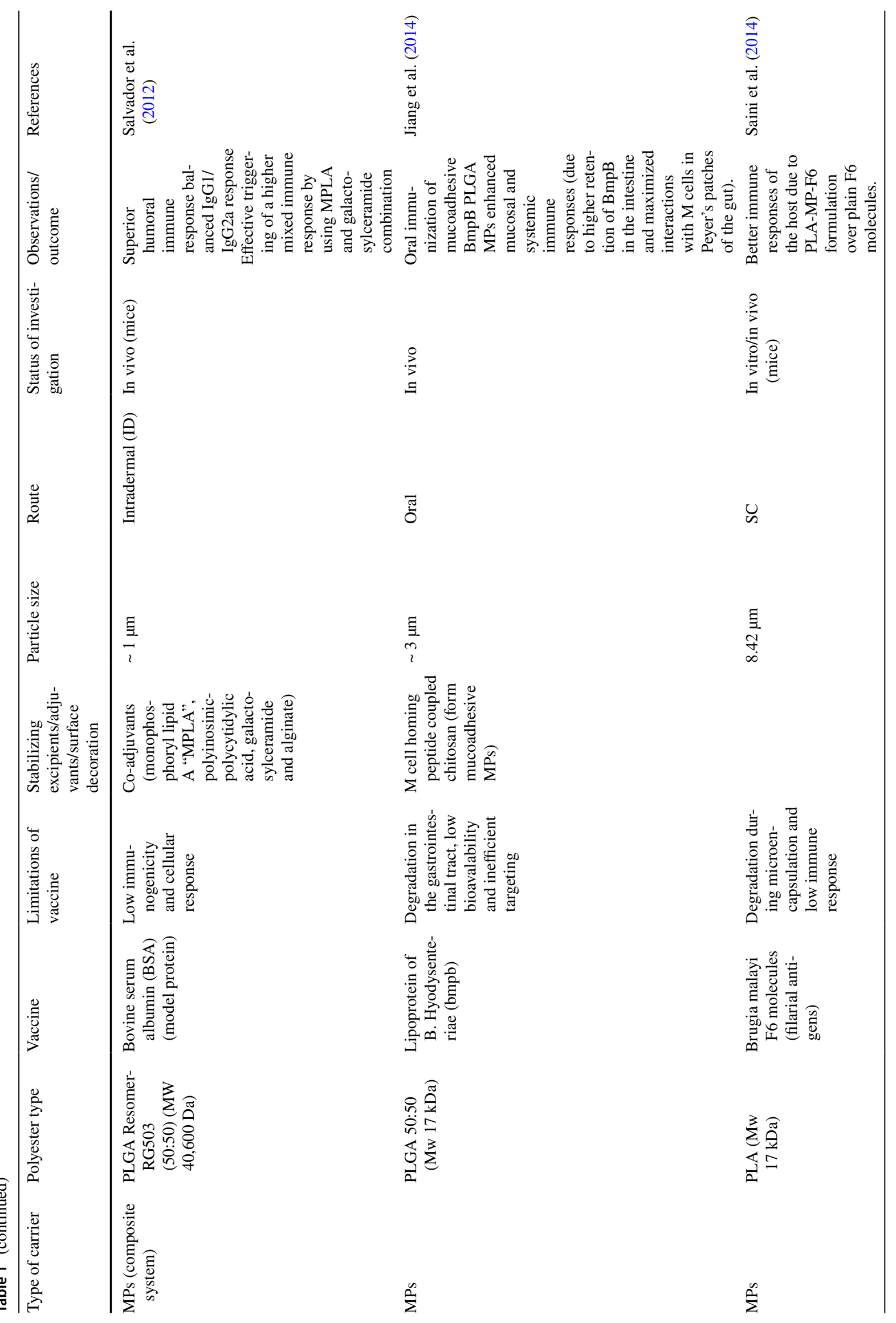




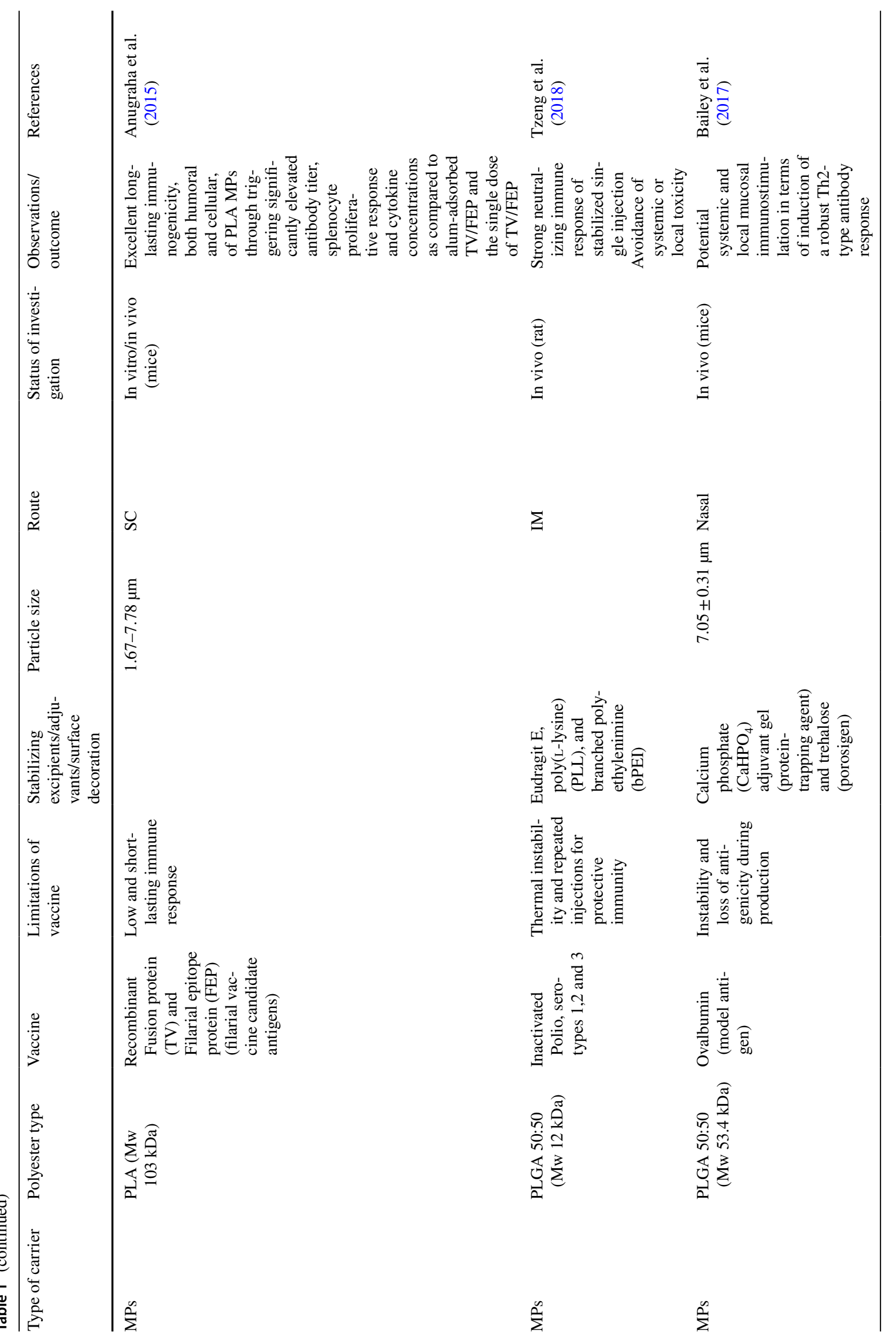


a focus on the biocompatibility of the prepared systems and their therapeutic outcomes.

\section{PLA and PLGA based MPs and NPs systems for drug delivery}

Past efforts have realized great achievements in therapeutic strategies using drugs, both small molecules and macromolecules, in combination with PLA and PLGA biomaterials (Makadia and Siegel 2011). In particular, polyesters based therapeutics gain success in improving chemotherapeutic efficacy, both in vitro and in vivo, and anti-inflammatory response for treatment of cancer (Hu and Zhang 2012) and inflammatory diseases (Danhier et al. 2012) respectively in various administration routes.

Bioinert and biodegradable PLA and PLGA drug carrier materials hold outstanding advantages, including (i) sustainable delivery (Mansor et al. 2018), (ii) proper control of drug release kinetics (iii) diminished fluctuations of blood drug concentrations (Makadia and Siegel 2011), (iv) augmented cellular uptake of NPs via endocytosis (Bi et al. 2016; Priemel et al. 2018), (v) enhanced stability (Xiong et al. 2016), (vi) optimal clinical utility (Lü et al. 2009) and (vii) improved medication adherence (Liu et al. 2006).

In recent years, researchers have become more focused on designing surface modified PLA and PLGA particulates, possessing prolonged systemic circulation time (Meng et al. 2018). The most relevant way to avoid RES recognition is the PEGylation, via masking hydrophobicity of the particles and imparting stealth characteristics by hydrophilic PEG brush (Mansor et al. 2018). Experimental research has also proved other favorable properties of PEGylated particles such as reducing aggregation while enhancing stability and biological potency (Goudarzi et al. 2018). Moreover, considerable interest has been conducted in the development of ligand coupled NPs like peptide, antibodies, and nucleotides ligands for enhanced localization and active targeting capabilities to specific organs or cells (Dinarvand et al. 2011). Examples of recent publications that have shown promising results towards effective sustained PLA and PLGA based MPs and NPs for drug delivery are listed in Table 2. An emphasis is placed on findings of investigations done to assess degradation and/or toxicity issues of the prepared DDS.

\section{PLA and PLGA based MPs and NPs systems for gene delivery}

Gene therapy interests the researchers of the scientific community by its potential in fighting diseases from their genetic source providing personalized medicine to the patients
(Naldini 2015). This specific therapy is therefore promising for the treatment of complex diseases such as chronic infections, cancer and inherited diseases, especially in substitution of standard treatments when they fail to cure the disease.

Many achievements have been reached in the field of gene delivery of a variety of nucleic acids such as pDNA (Baoum et al. 2010), mRNA (Yasar et al. 2018), siRNA, and microRNA. These nucleic acids can both introduce genes that encode a functional protein that is vital in preventing disease progression or block the translation of specific mRNAs to prevent a toxic effect. Multiple obstacles are present after the administration of nucleic acids such as the presence of nuclease, the nucleic acid instability, biological membrane and endocytosis. The overcome of these obstacles can be achieved by the use of nanotechnology and the incorporation of nucleic acid in different nano and microparticles (Wong et al. 2017; Xiao et al. 2019).

Biodegradable polyesters including PLA and PLGA were highly investigated for preparing gene delivery vectors (Kumari et al. 2010). However, for delivery of therapeutic genes, there is a great challenge of formulating PLA and PLGA particles containing a high payload, owing to their negatively charged backbone. The loading of nucleic acids to PLA and PLGA NPs could be done by either direct encapsulation using double emulsion solvent evaporation technique (Mok and Park 2008) or by the pre cationization (adding cationic polymers) of polyester NPs to enhance the encapsulation efficiency of nucleic acids and accelerate their release (Luten et al. 2008). Cationization of polyester NPs can be done by incorporating cationic molecules such as polyethylenimine (PEI) (Frede et al. 2016; Kolte et al. 2017), chitosan (Tahara et al. 2011), polyarginine (Zhao et al. 2012), poly(2dimethylaminoethyl methacrylate (pDMAEMA) (Qian et al. 2014), cationic lipids (Dioleyltrimethylammonium propane "DOTAP"-Dioctadecenyltrimethylammoniumpropane "DOTMA") (Yasar et al. 2018; Zhu et al. 2015), Dimethylaminoethane carbamoyl cholesterol (DC-Chol) (Baoum et al. 2010; Gwak et al. 2016) and cationic cell-penetrating peptide (CCCP) (Jain et al. 2015).

It is well known that the smaller the particle size, the more efficient the gene delivery, however, PLGA particles are easily phagocytosed by immune cells when prepared in size less than $10 \mu \mathrm{m}$ (Oyewumi et al. 2010). Several trials have been done to modify or sustain the release of nucleic acids from PLA and PLGA based systems. However, their hydrophobic nature renders extended nucleic acid release not feasible being rapidly removed from circulation after parenteral administration (Dinarvand et al. 2011). In order to solve the previously mentioned obstacle, many strategies have been explored including PEGylation, copolymerization with hydrophilic polymers, NPs coating with a surfactant, lipid and targeting ligands (Jain et al. 2015). 


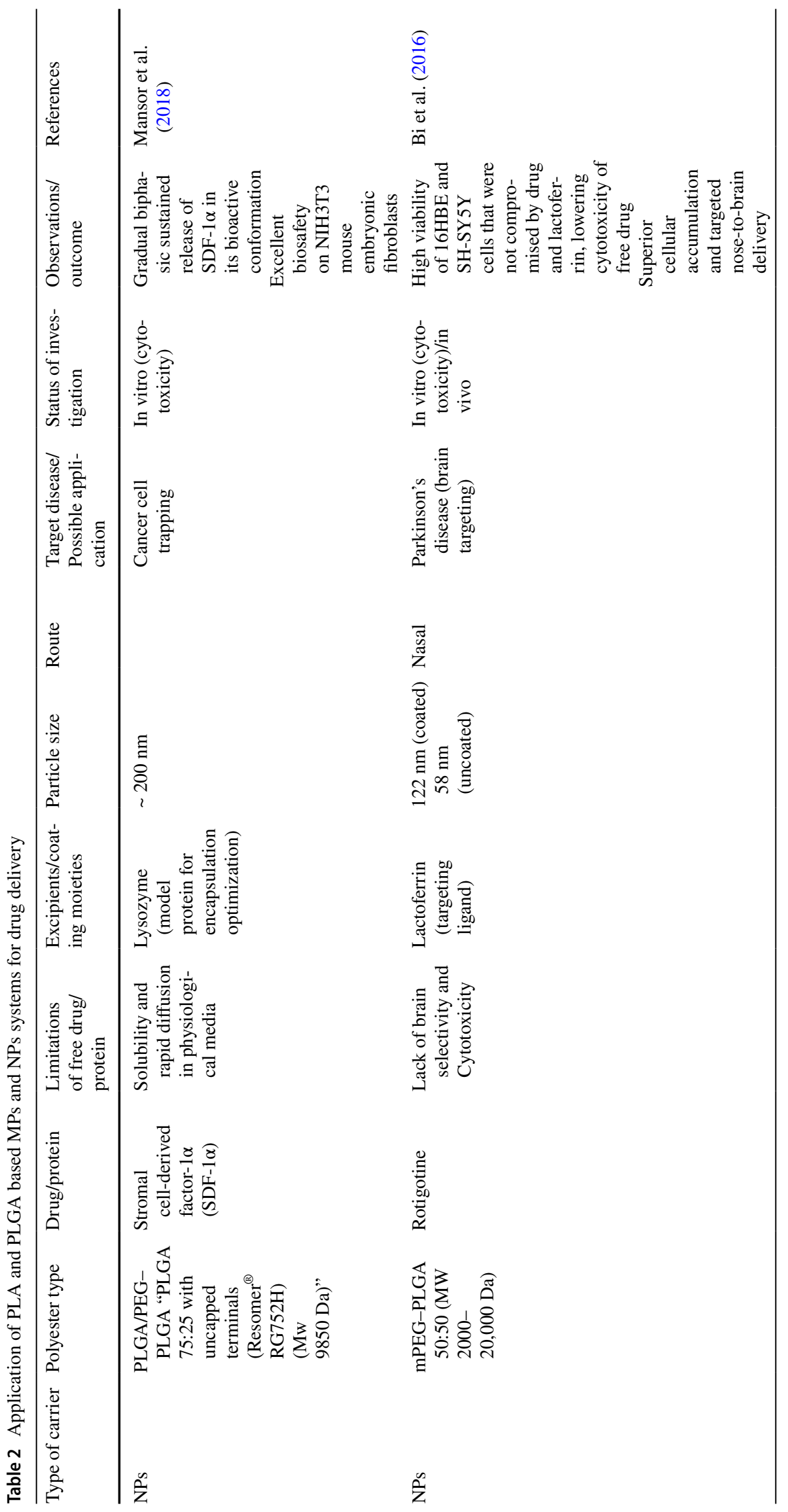




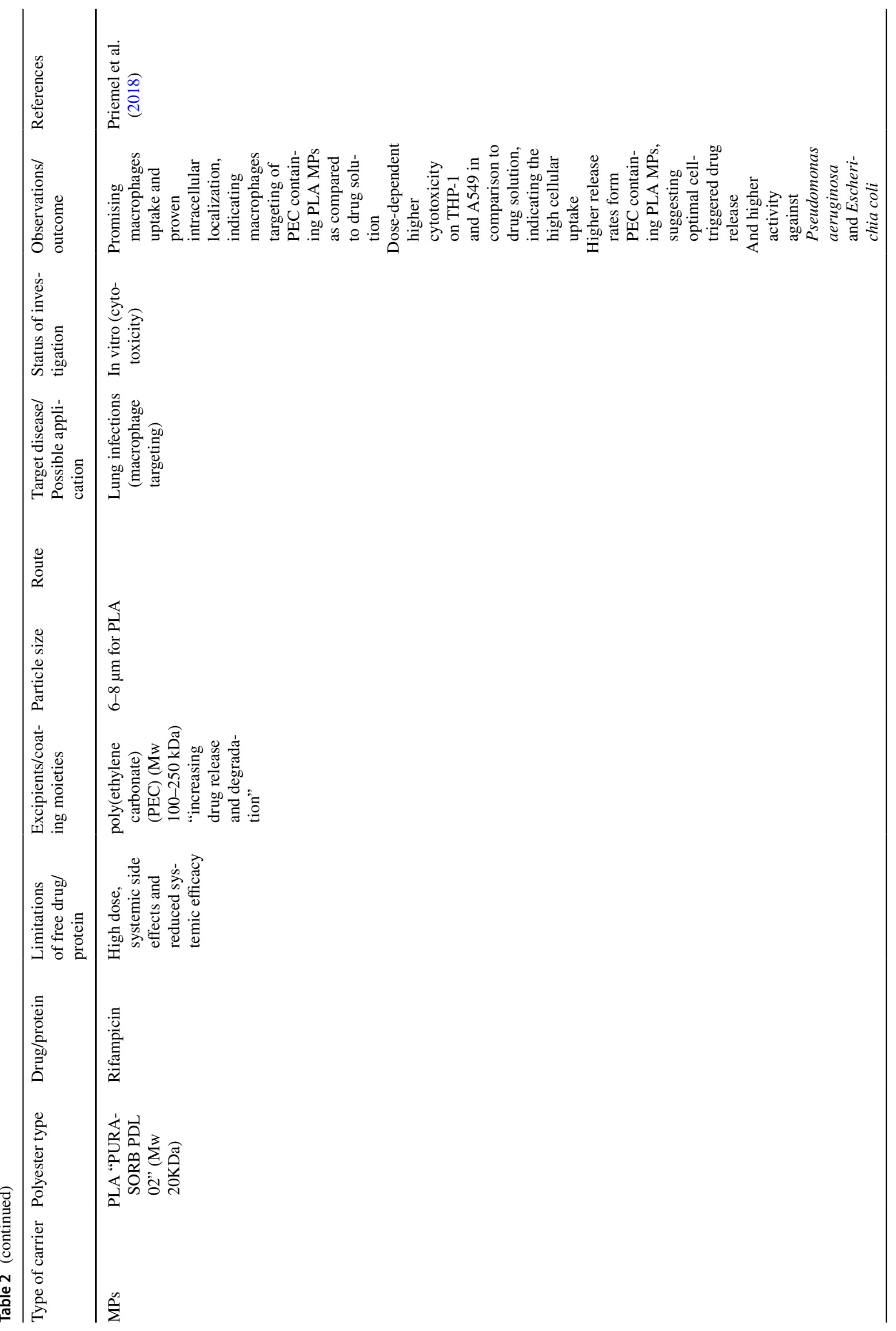




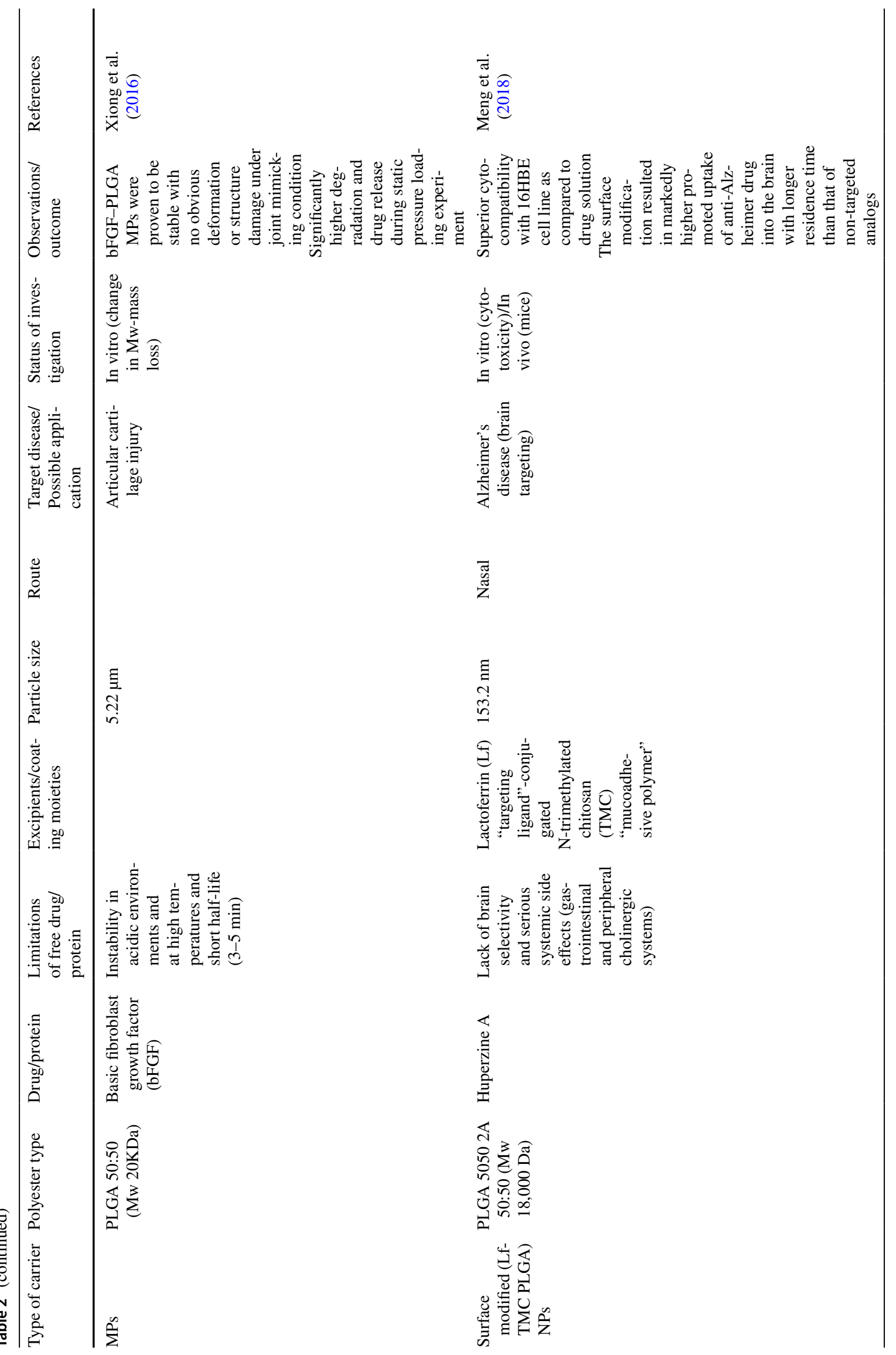




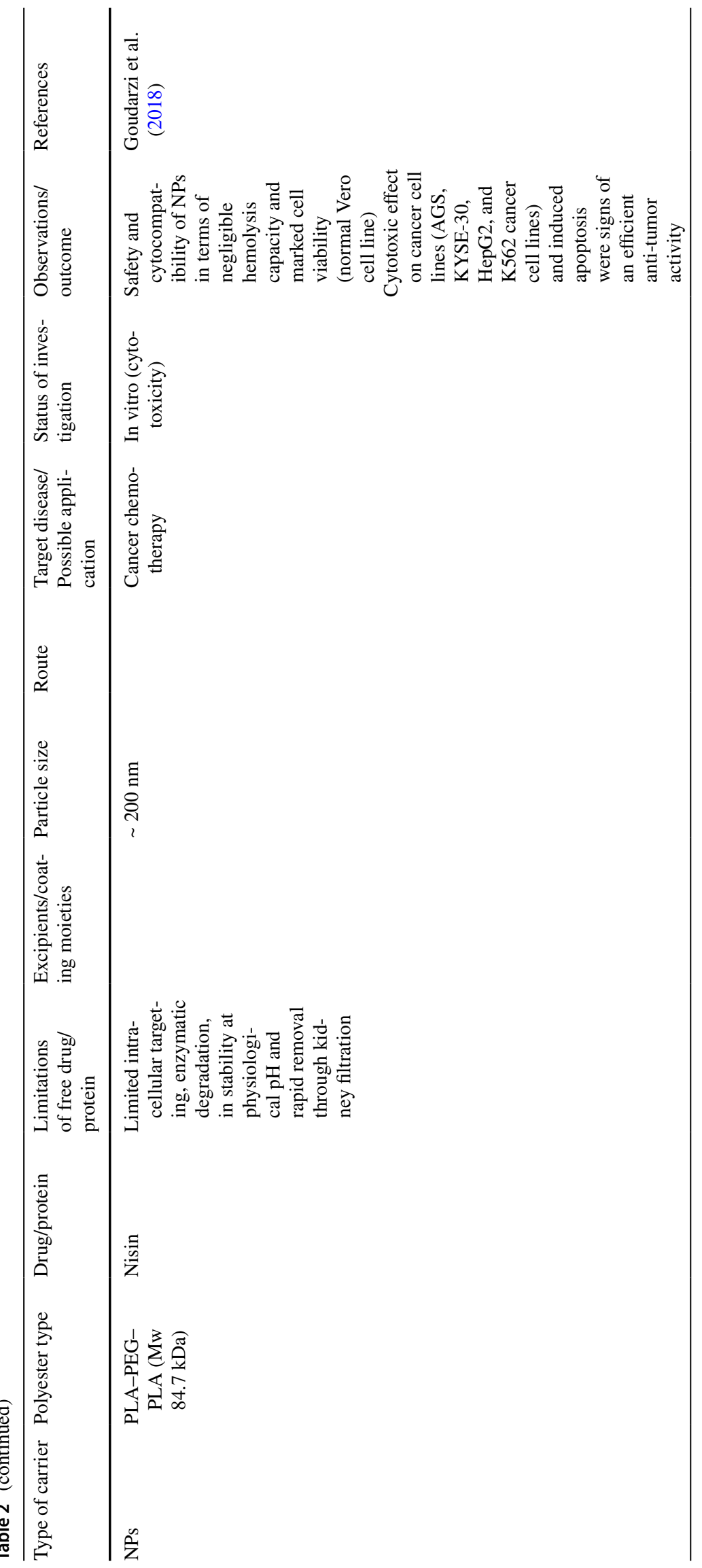




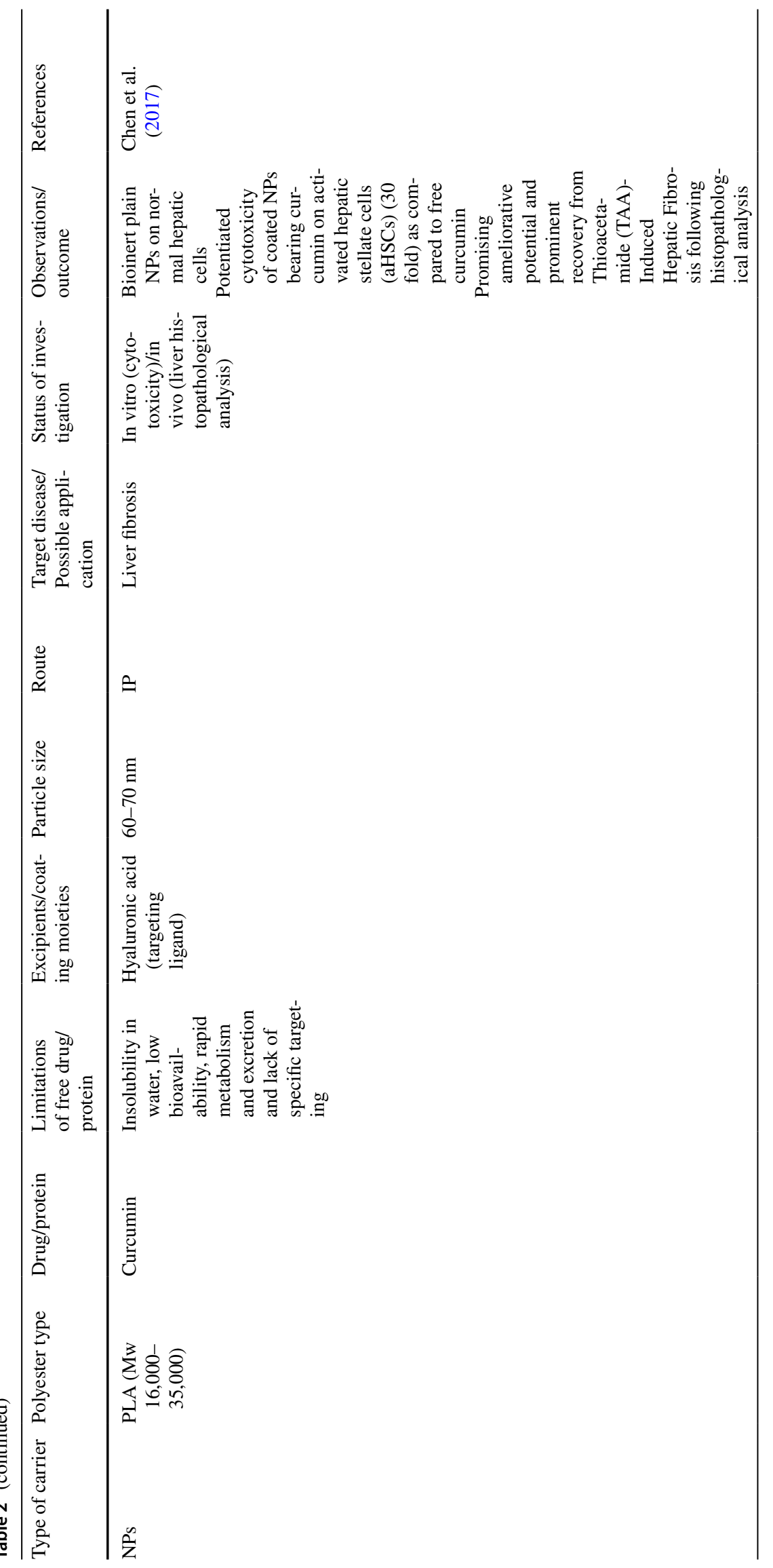




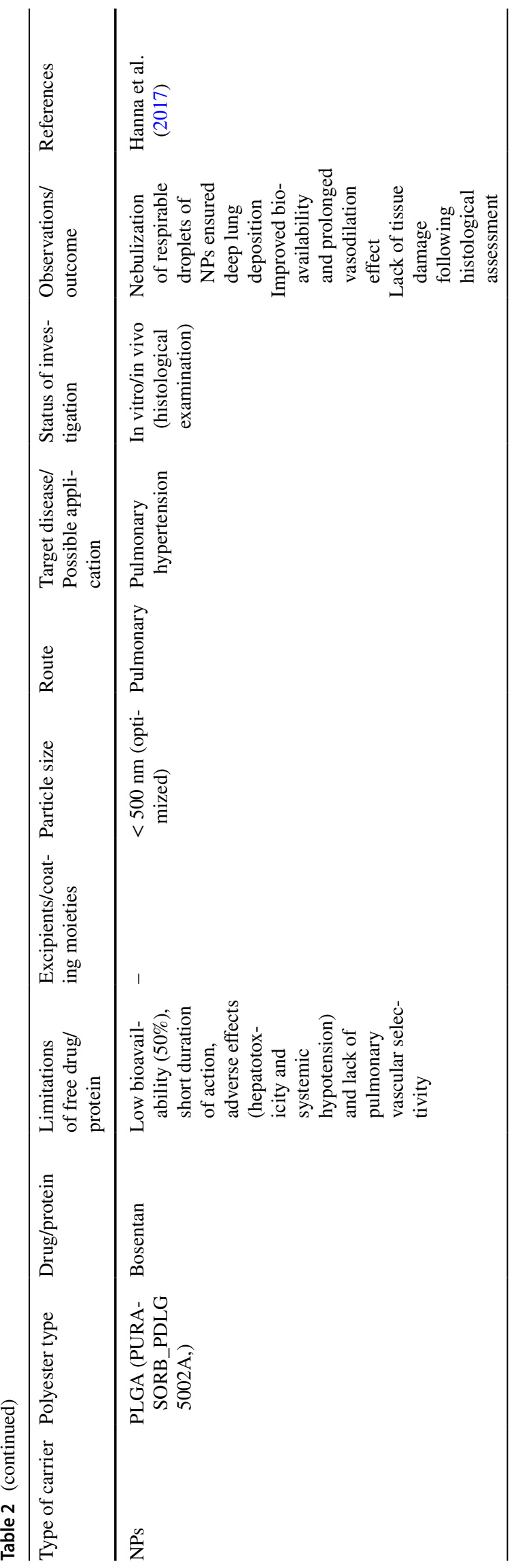




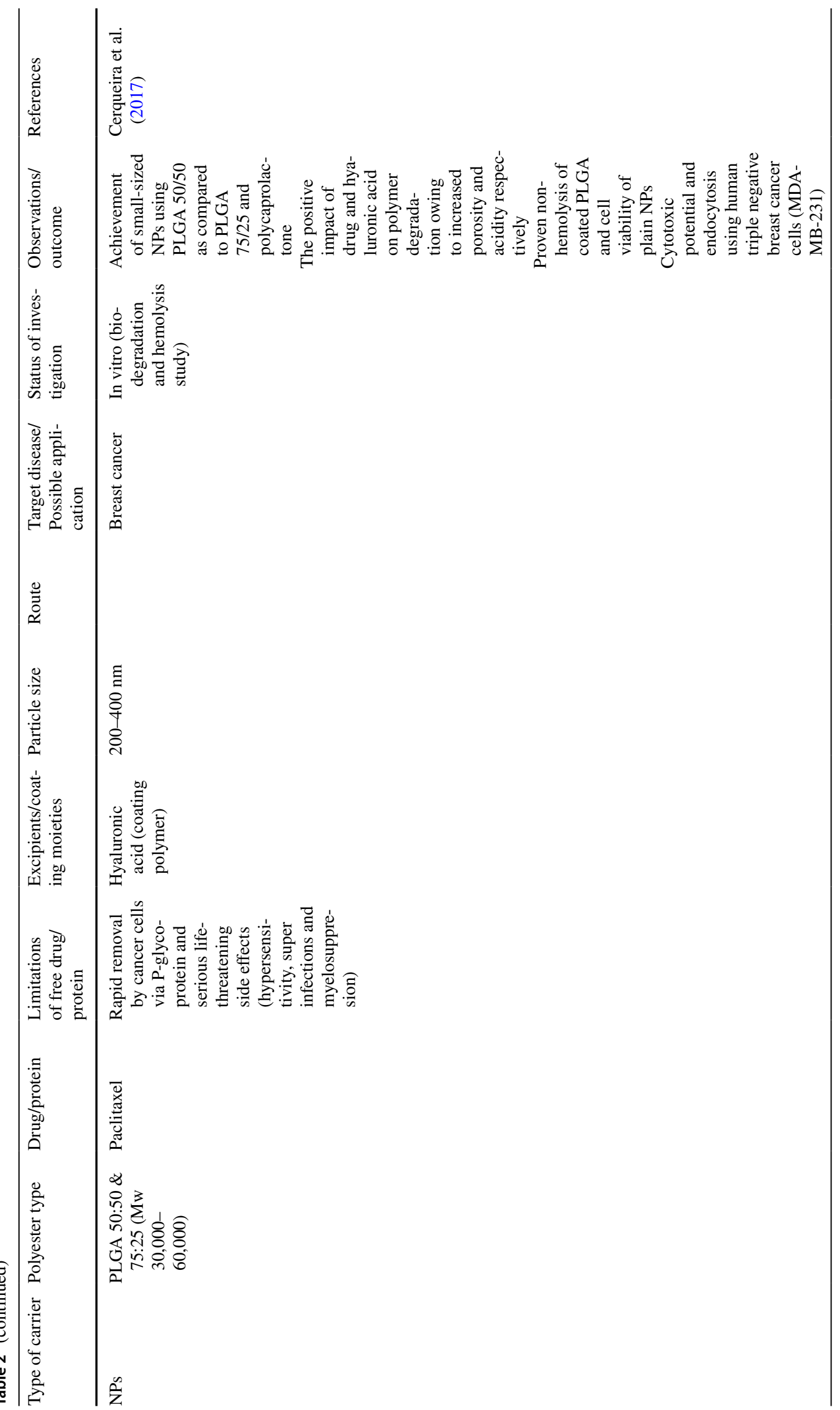




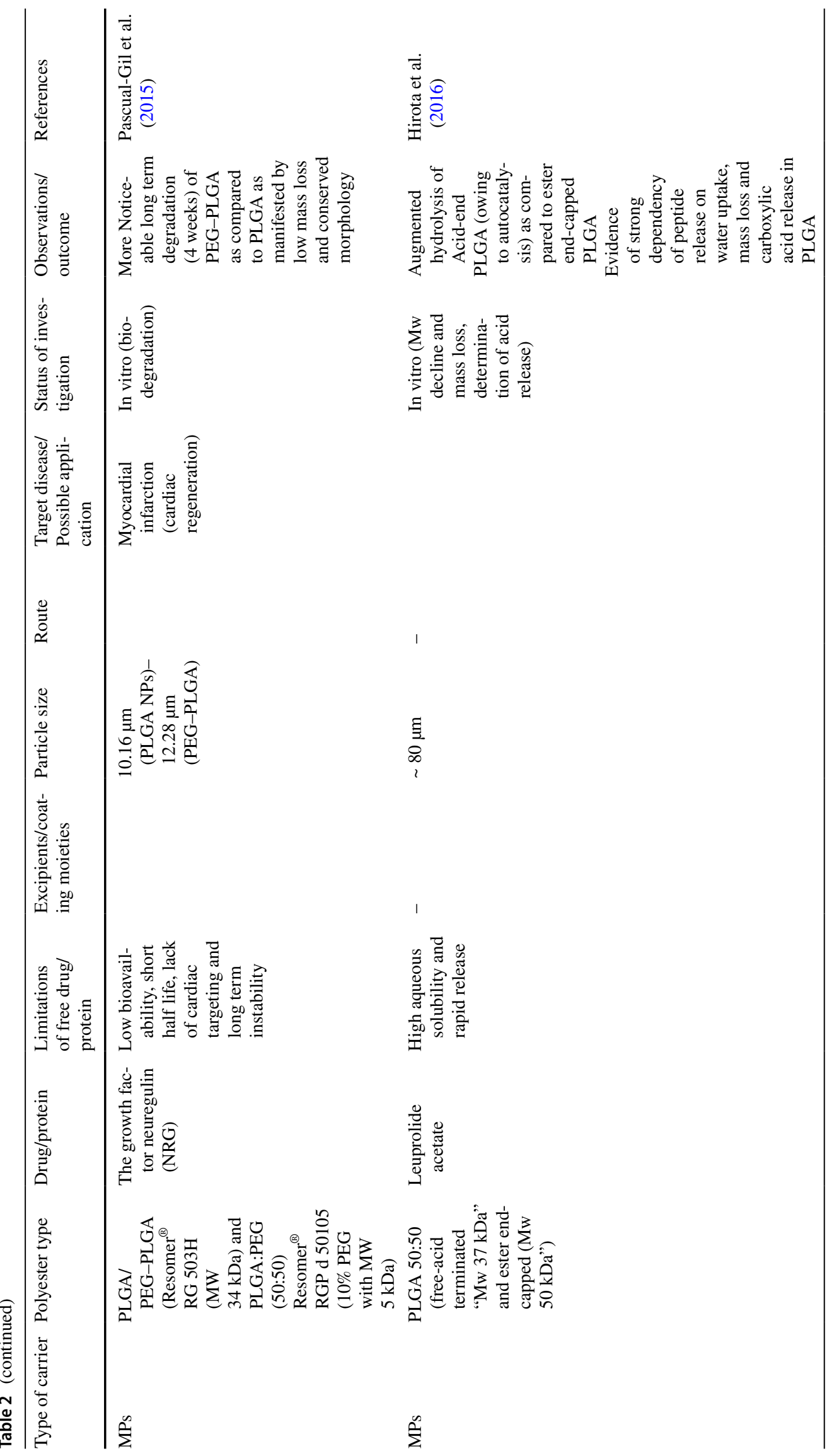




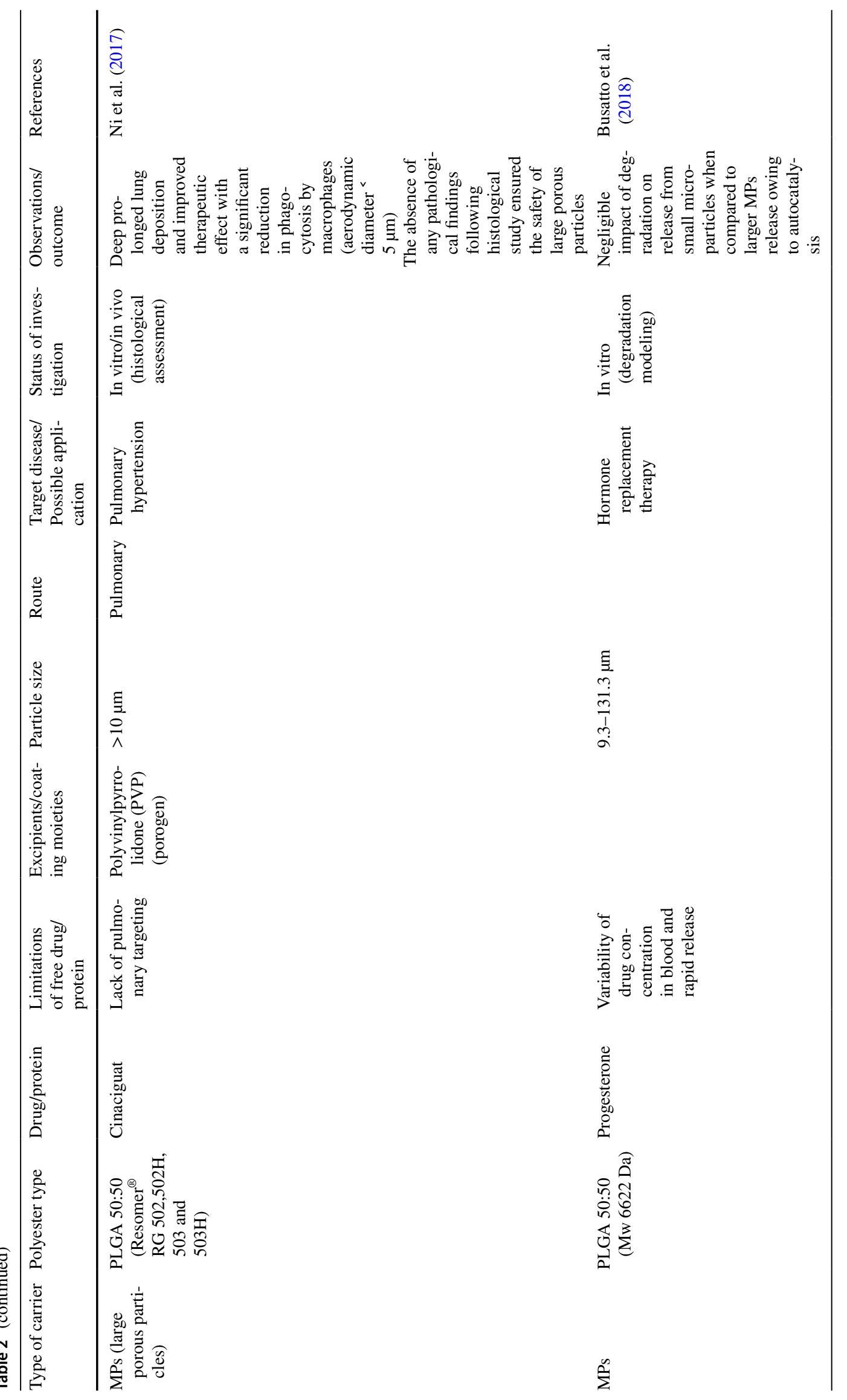




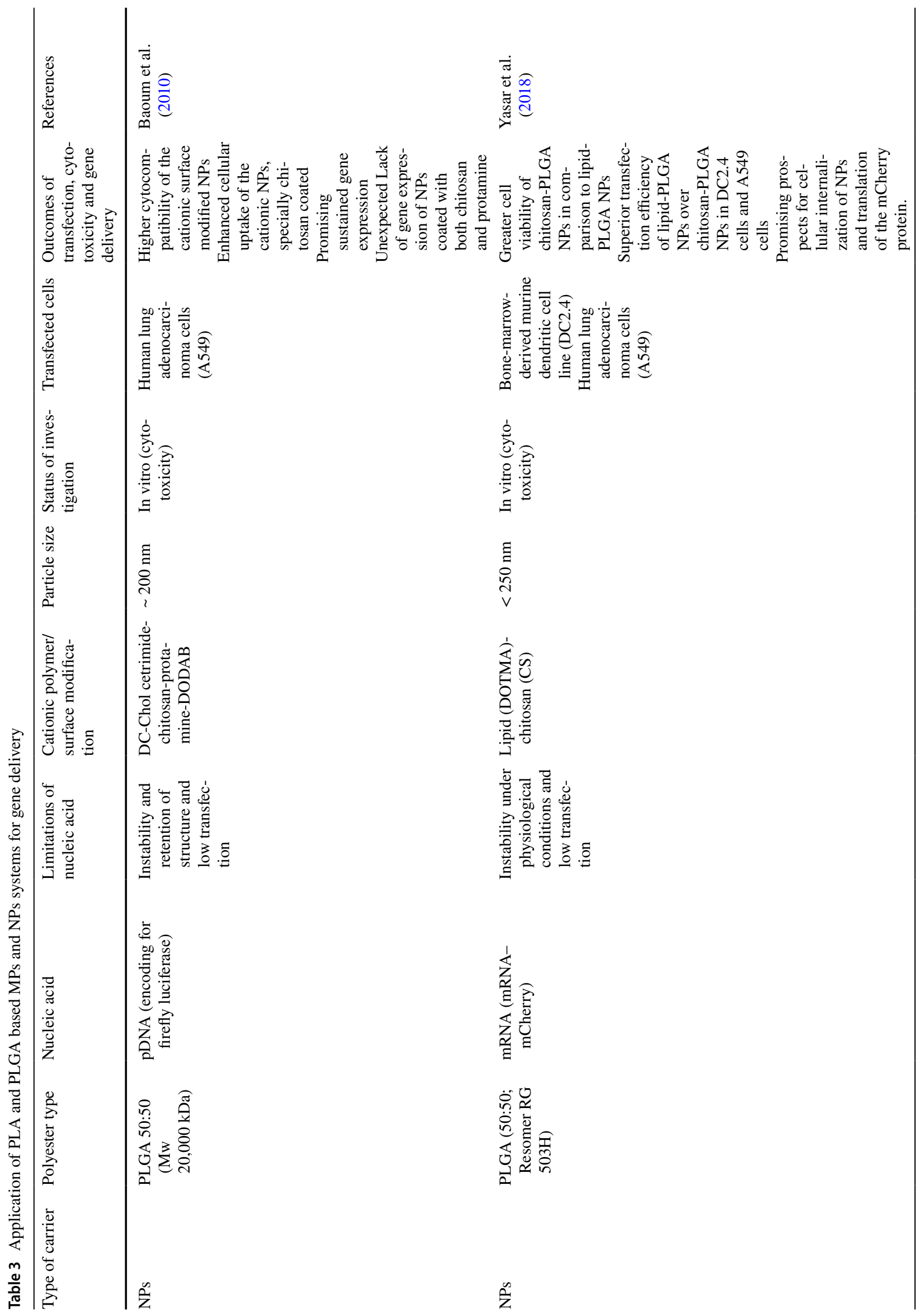




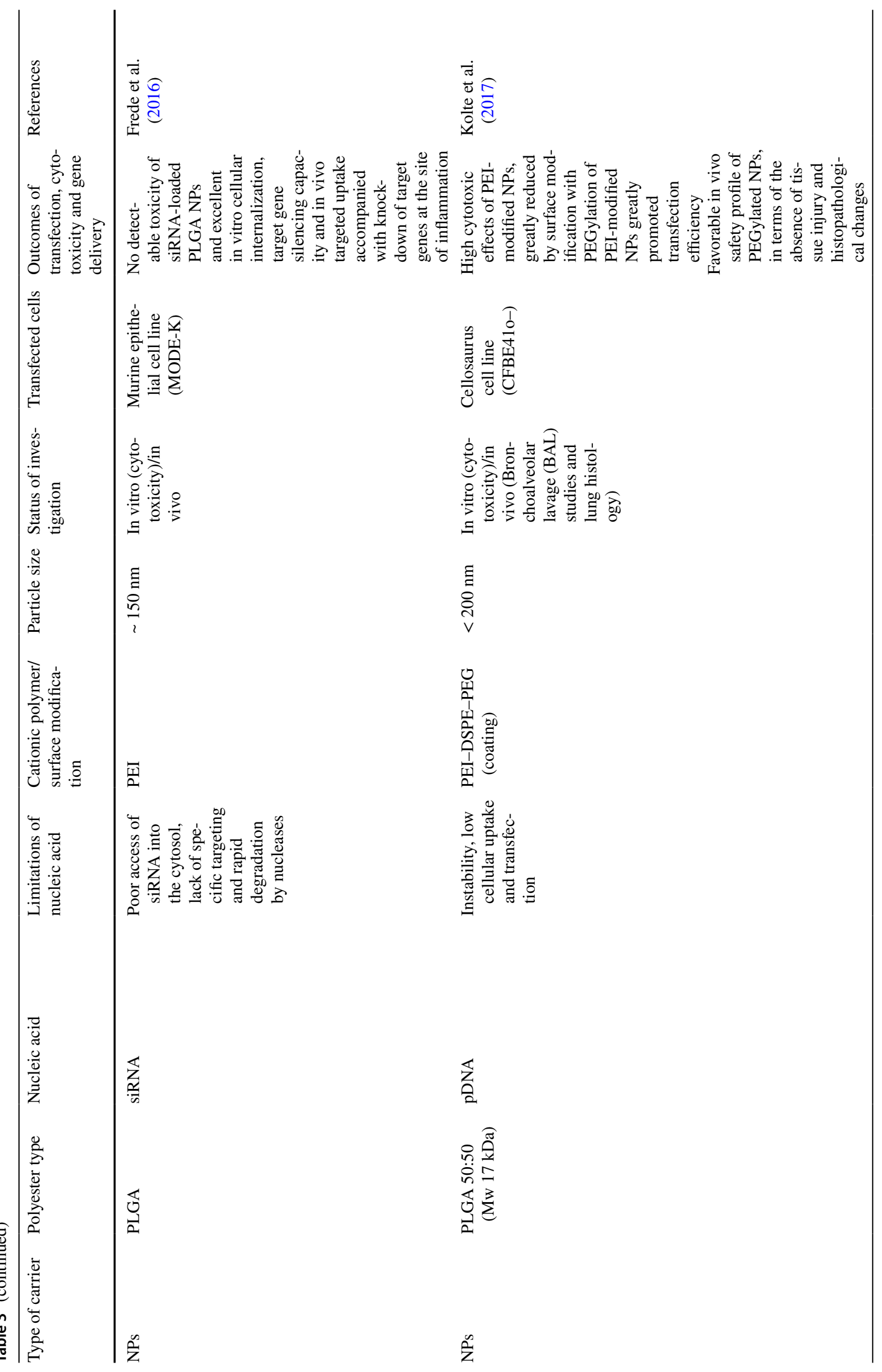




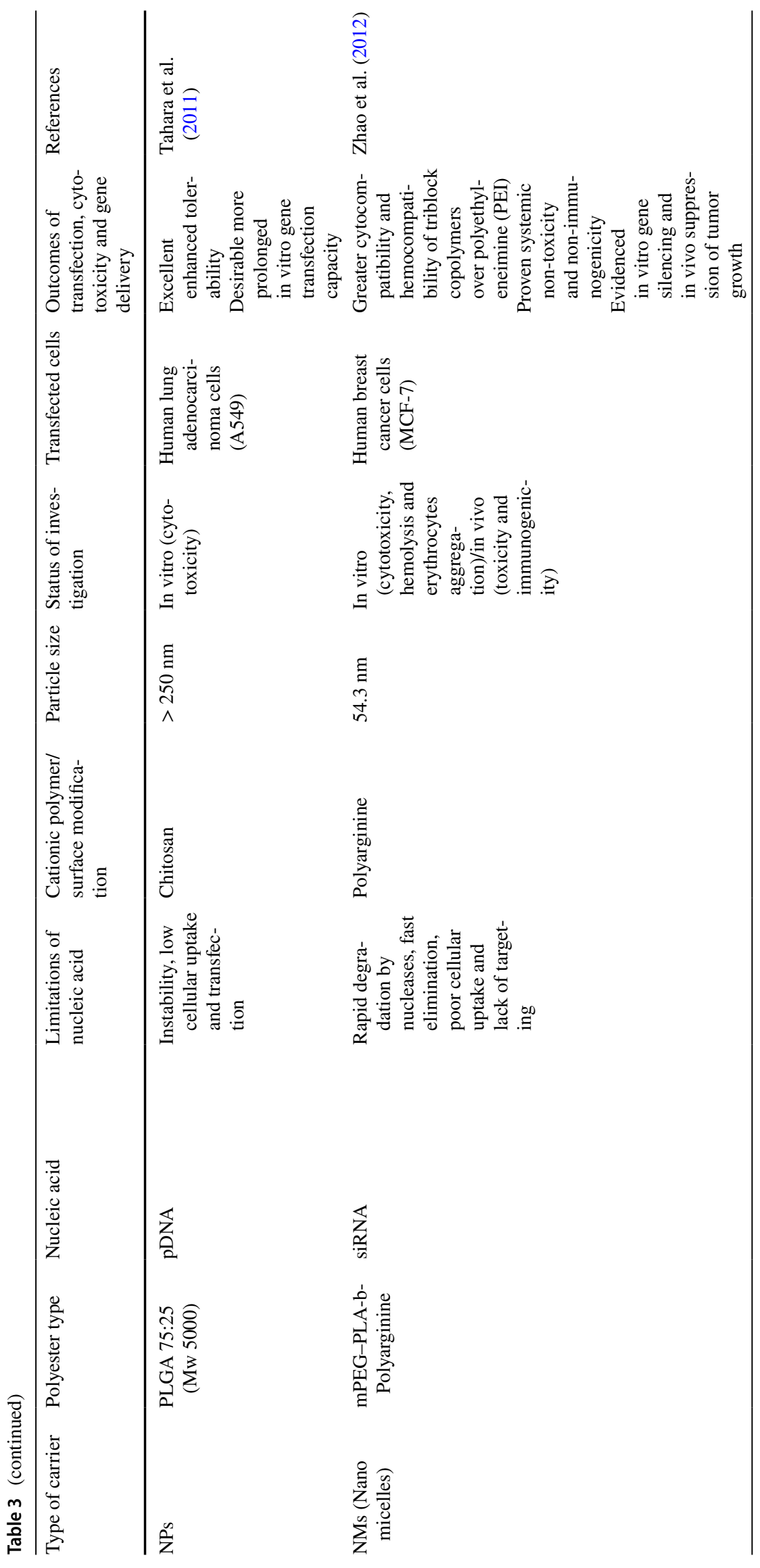




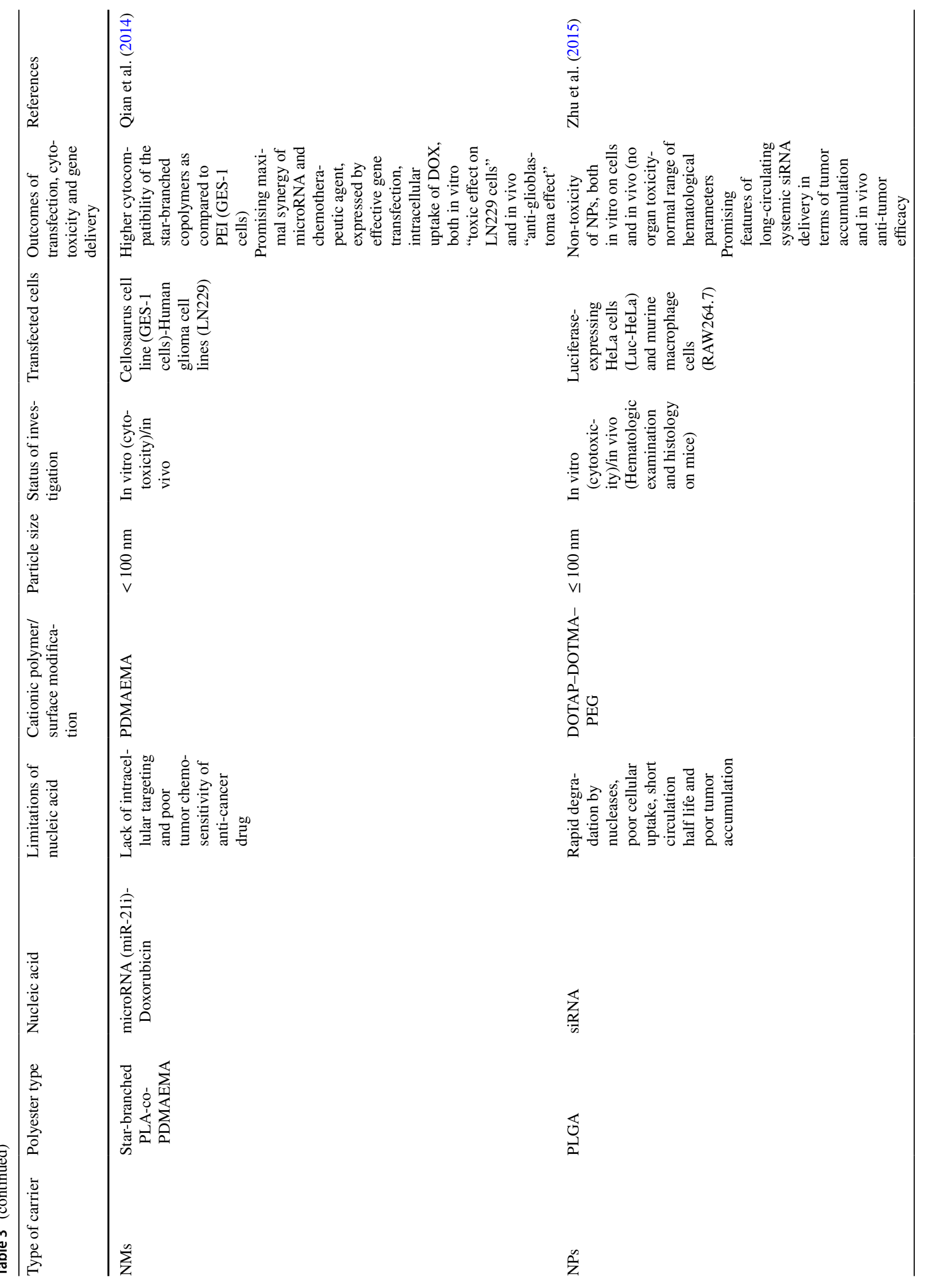




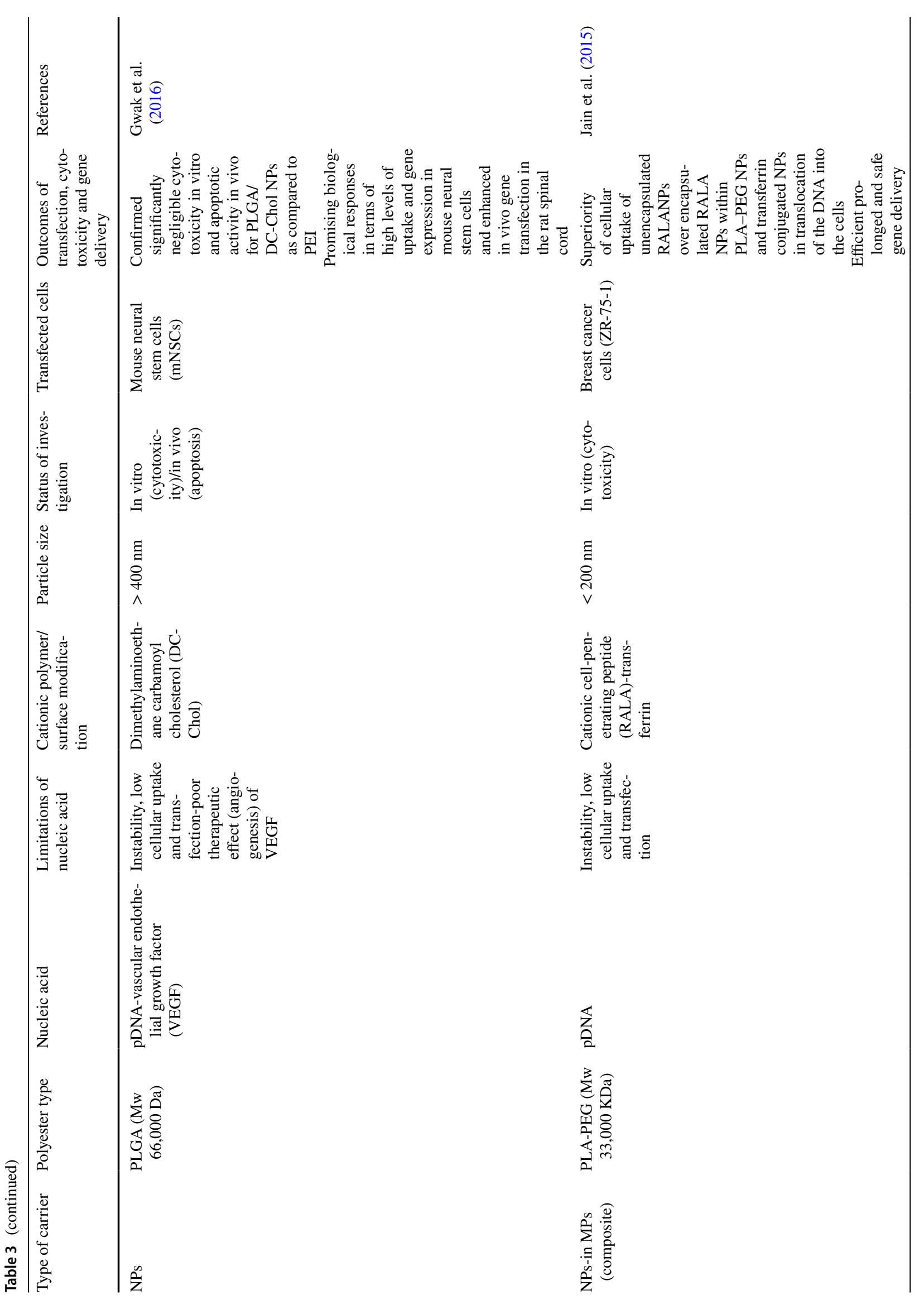




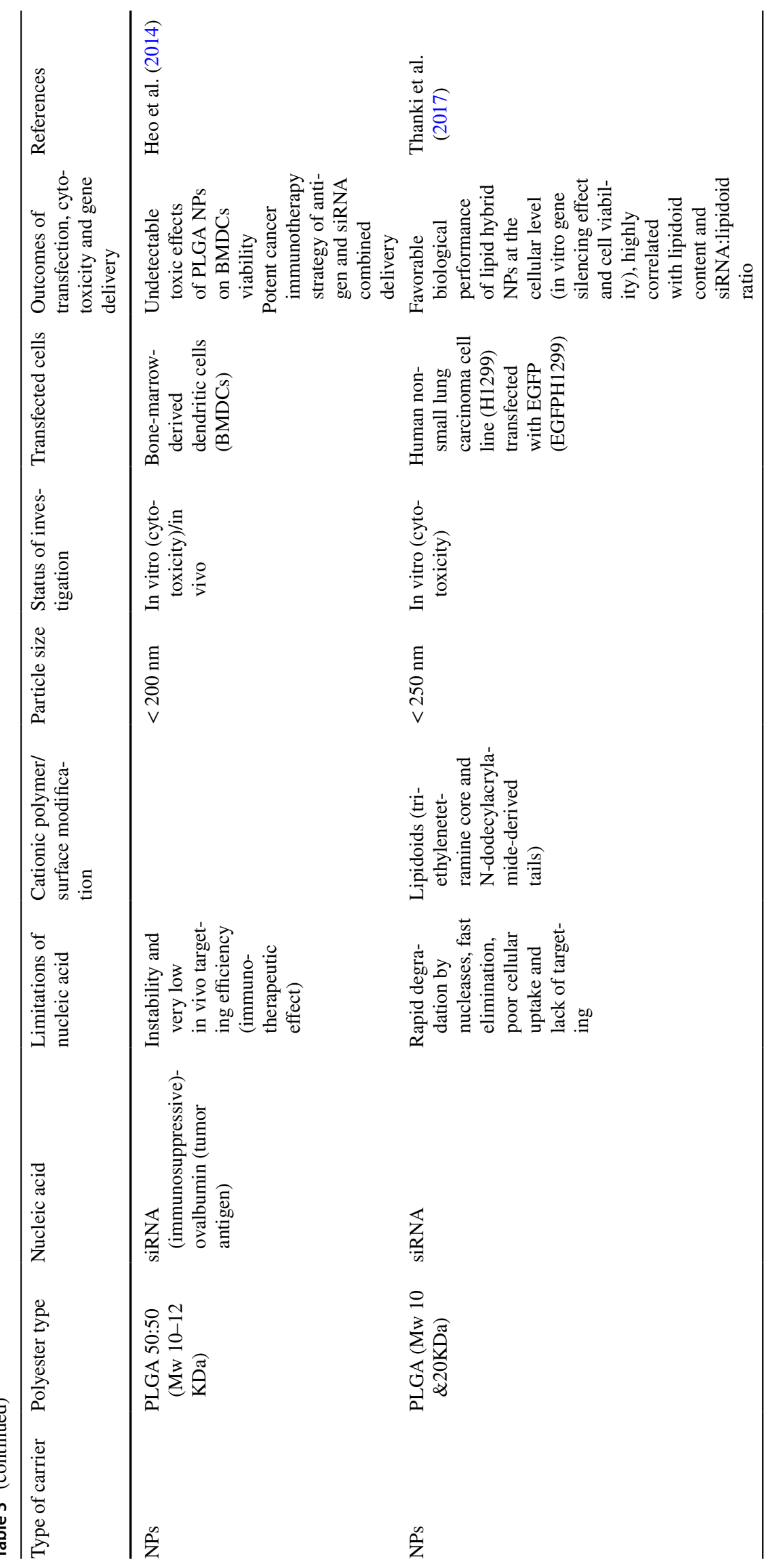




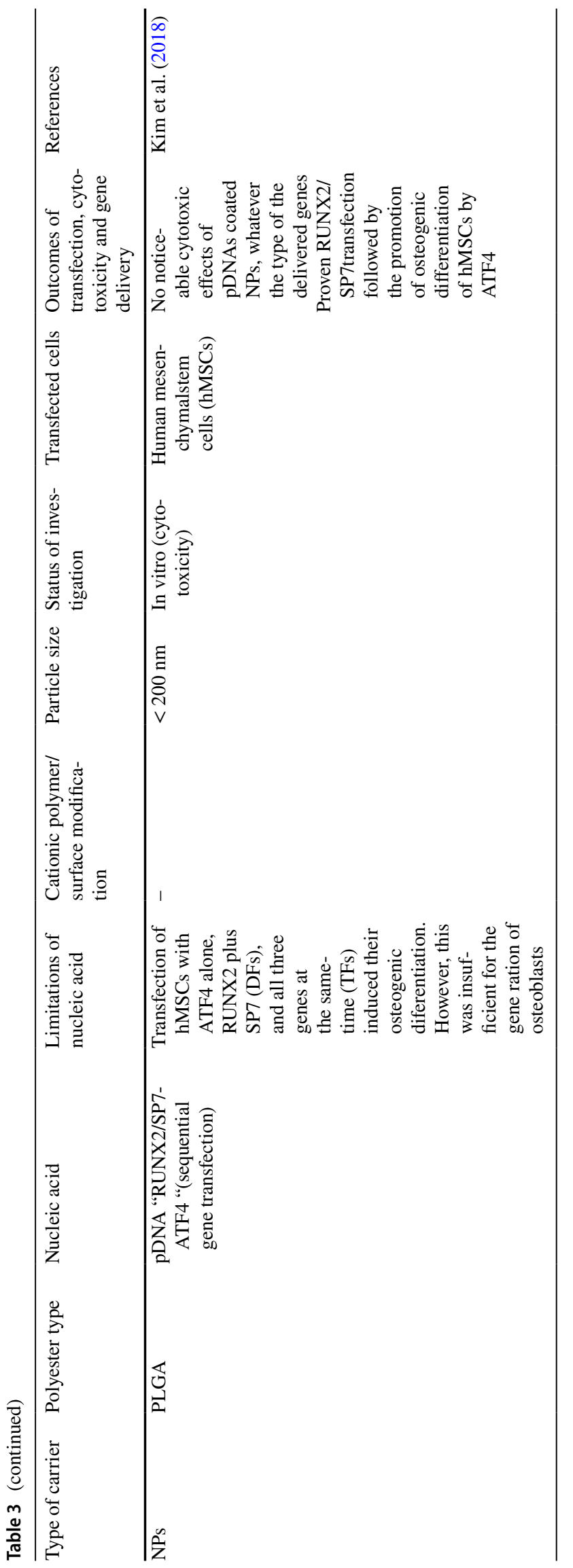

PLA and PLGA based NPs loaded with nucleic acids can be delivered to various animal models through different routes of administration such as IM, ID, SC and oral (Bala et al. 2004). Outstanding features of non-immunogenicity and non-toxicity of PLA and PLGA have been keyed the researchers to design PLA and PLGA particles loaded with nucleic acids cargo, such as oligonucleotides, plasmid DNA, and small interfering RNA (siRNA), as an alternative to immunogenic and toxic viral vectors (Xu and Zhang 2009). In addition to previously mentioned PLA and PLGA merits, such biomaterials could give favorable outcomes of potentiating poor intrinsic transfection efficiency of nucleic acids (Heo et al. 2014; Kolte et al. 2017; Xu and Zhang 2009), providing long term gene expression or gene silencing (Jain et al. 2015; Zhu et al. 2015), enhancing translocation inside the cell (Jain et al. 2015), maximizing protection from enzymatic degradation and enhancing gene delivery system cytocompatibility and tolerability (Baoum et al. 2010; Qian et al. 2014; Zhao et al. 2012).

In the future, nanotechnology and gene therapy will be inseparable because, the successful development of efficient non-toxic, non-immunogenic, and biodegradable NPs will improve the efficiency of gene therapy, resulting in breakthroughs for the cure of specific diseases (Wong et al. 2017). Indeed, the successful development and optimization of therapeutic nuclei acids and subsequent clinical gene therapy trials seem to pave the way for recent expansion of market authorization (Lächelt and Wagner 2015).

Special focuses on some research papers, covering the application of PLA and PLGA based MPs and NPs systems that are combined with different cationic polymers for gene delivery as well as addressing safety issue, are summarized in Table 3.

\section{Conclusion}

Development of new DDS with excellent safety profile, avoiding unwanted tissue responses and tunable degradation is highly warranted. Biocompatibility and biodegradability of PLA and PLGA polymers pose them as a promising choice in many local and systemic therapeutic applications. Their degradation rate can be traced and modeled using different techniques and was revealed to affect drug release kinetics from PLA and PLGA-based DDS. Insights into the described mechanisms of sustained drug release, PLA and PLGA MPs and NPs have been utilized for vaccine development as well as encapsulating various conventional drugs, proteins and nucleic acids for gene delivery. Based on the abovementioned data and therapeutic outcomes, the idea of the technology transfer of a number of new DDS could gain grounds in the near future. New therapies might be seen in 
clinics, specifically in the fields of vaccination and cancer immunotherapy.

Acknowledgements This work was supported by Department of Pharmacy and Industrial Pharmacy, Faculty of Pharmacy, Ain Shams University, Cairo-Egypt.

\section{Compliance with ethical standards}

Conflict of interest The authors report no conflicts of interest in this work.

Statement of human and animal rights This article does not contain any studies with human or animal subjects performed by any of the authors.

\section{References}

Abedalwafa M, Wang F, Wang L, Li C (2013) Biodegradable polyepsilon-caprolactone (PCL) for tissue engineering applications: a review. Rev Adv Mater Sci 34:123-140

Agrahari V, Agrahari V, Mitra AK (2016) Nanocarrier fabrication and macromolecule drug delivery: challenges and opportunities. Therap Deliv 7:257-278

Ahmed J, Varshney SK (2011) Polylactides-chemistry, properties and green packaging technology: a review. Int J Food Prop 14:37-58

Alexis F (2005) Factors affecting the degradation and drug-release mechanism of poly (lactic acid) and poly [(lactic acid)-co(glycolic acid)]. Polym Int 54:36-46

Alsaheb RAA, Aladdin A, Othman NZ, Malek RA, Leng OM, Aziz R, El Enshasy HA (2015) Recent applications of polylactic acid in pharmaceutical and medical industries. J Chem Pharm Res 7:51-63

Anderson JM, Shive MS (1997) Biodegradation and biocompatibility of PLA and PLGA microspheres. Adv Drug Deliv Rev 28:5-24

Anderson JM, Rodriguez A, Chang DT (2008) Foreign body reaction to biomaterials. Semin Immunol 20:86-100

Antheunis H, van der Meer J-C, de Geus M, Kingma W, Koning CE (2009) Improved mathematical model for the hydrolytic degradation of aliphatic polyesters. Macromolecules 42:2462-2471

Antheunis H, van der Meer J-C, de Geus M, Heise A, Koning CE (2010) Autocatalytic equation describing the change in molecular weight during hydrolytic degradation of aliphatic polyesters. Biomacromol 11:1118-1124

Anugraha G, Madhumathi J, Prita PJJ, Kaliraj P (2015) Biodegradable poly-1-lactide based microparticles as controlled release delivery system for filarial vaccine candidate antigens. Eur J Pharmacol 747:174-180

Ashhurst AS, Parumasivam T, Chan JGY, Lin LC, Flórido M, West NP, Chan H-K, Britton WJ (2018) PLGA particulate subunit tuberculosis vaccines promote humoral and Th17 responses but do not enhance control of mycobacterium tuberculosis infection. PLoS ONE 13:e0194620

Bailey BA, Desai K-GH, Ochyl LJ, Ciotti SM, Moon JJ, Schwendeman SP (2017) Self-encapsulating poly (lactic-co-glycolic acid) (PLGA) microspheres for intranasal vaccine delivery. Mol Pharm 14:3228-3237

Bala I, Hariharan S, Kumar MR (2004) PLGA nanoparticles in drug delivery: the state of the art. Crit Rev Ther Drug Carr Syst $21: 387-422$

Bao X, Gao M, Xu H, Liu K-X, Zhang C-H, Jiang N, Chu Q-C, Guan $X$, Tian Y (2015) A novel oleanolic acid-loaded PLGA-TPGS nanoparticle for liver cancer treatment. Drug Dev Ind Pharm 41:1193-1203

Baoum A, Dhillon N, Buch S, Berkland C (2010) Cationic surface modification of PLG nanoparticles offers sustained gene delivery to pulmonary epithelial cells. J Pharm Sci 99:2413-2422

Bawa KK, Jazani AM, Shetty C, Oh JK (2018) PLA-based triblock copolymer micelles exhibiting dual acidic $\mathrm{pH} /$ reduction responses at dual core and core/corona interface locations. Macromol Rapid Commun 39:1800477

Bhardwaj U, Sura R, Papadimitrakopoulos F, Burgess DJ (2010) PLGA/PVA hydrogel composites for long-term inflammation control following sc implantation. Int J Pharm 384:78-86

Bi C, Wang A, Chu Y, Liu S, Mu H, Liu W, Wu Z, Sun K, Li Y (2016) Intranasal delivery of rotigotine to the brain with lactoferrin-modified PEG-PLGA nanoparticles for Parkinson's disease treatment. Int J Nanomed 11:6547

Brown A, Zaky S, Ray H Jr, Sfeir C (2015) Porous magnesium/ PLGA composite scaffolds for enhanced bone regeneration following tooth extraction. Acta Biomater 11:543-553

Busatto C, Pesoa J, Helbling I, Luna J, Estenoz D (2018) Effect of particle size, polydispersity and polymer degradation on progesterone release from PLGA microparticles: experimental and mathematical modeling. Int J Pharm 536:360-369

Cerqueira BBS, Lasham A, Shelling AN, Al-Kassas R (2017) Development of biodegradable PLGA nanoparticles surface engineered with hyaluronic acid for targeted delivery of paclitaxel to triple negative breast cancer cells. Mater Sci Eng, C 76:593-600

Champion JA, Walker A, Mitragotri S (2008) Role of particle size in phagocytosis of polymeric microspheres. Pharm Res 25:1815-1821

Chen Y-N, Hsu S-L, Liao M-Y, Liu Y-T, Lai C-H, Chen J-F, Nguyen M-H, Su Y-H, Chen S-T, Wu L-C (2017) Ameliorative effect of curcumin-encapsulated hyaluronic acid-PLA nanoparticles on thioacetamide-induced murine hepatic fibrosis. Int J Environ Res Public Health 14:11

Clawson C, Huang C-T, Futalan D, Seible DM, Saenz R, Larsson M, Ma W, Minev B, Zhang F, Ozkan M (2010) Delivery of a peptide via poly(D,L-lactic-co-glycolic) acid nanoparticles enhances its dendritic cell-stimulatory capacity. Nanomedicine 6:651-661

Cruz LJ, Tacken PJ, Eich C, Rueda F, Torensma R, Figdor CG (2017) Controlled release of antigen and toll-like receptor ligands from PLGA nanoparticles enhances immunogenicity. Nanomedicine 12:491-510

D'Souza S, Faraj JA, Dorati R, DeLuca PP (2015) Enhanced degradation of lactide-co-glycolide polymer with basic nucleophilic drugs. Adv Pharm. https://doi.org/10.1155/2015/154239

Dailey L, Jekel N, Fink L, Gessler T, Schmehl T, Wittmar M, Kissel T, Seeger W (2006) Investigation of the proinflammatory potential of biodegradable nanoparticle drug delivery systems in the lung. Toxicol Appl Pharmacol 215:100-108

Dang TT, Bratlie KM, Bogatyrev SR, Chen XY, Langer R, Anderson DG (2011) Spatiotemporal effects of a controlled-release antiinflammatory drug on the cellular dynamics of host response. Biomaterials 32:4464-4470

Danhier F, Ansorena E, Silva JM, Coco R, Le Breton A, Préat V (2012) PLGA-based nanoparticles: an overview of biomedical applications. J Control Release 161:505-522

Demento SL, Cui W, Criscione JM, Stern E, Tulipan J, Kaech SM, Fahmy TM (2012) Role of sustained antigen release from nanoparticle vaccines in shaping the $\mathrm{T}$ cell memory phenotype. Biomaterials 33:4957-4964

Derman S, Mustafaeva ZA, Abamor ES, Bagirova M, Allahverdiyev A (2015) Preparation, characterization and immunological evaluation: canine parvovirus synthetic peptide loaded PLGA nanoparticles. J Biomed Sci 22:89 
Dhandayuthapani B, Yoshida Y, Maekawa T, Kumar DS (2011) Polymeric scaffolds in tissue engineering application: a review. Int J Polym Sci. https://doi.org/10.1155/2011/290602

Dinarvand R, Sepehri N, Manoochehri S, Rouhani H, Atyabi F (2011) Polylactide-co-glycolide nanoparticles for controlled delivery of anticancer agents. Int J Nanomed 6:877

Dischert W, Soucaille P (2015) Method for producing high amount of glycolic acid by fermentation. Google Patents

Dorati R, Genta I, Colonna C, Modena T, Pavanetto F, Perugini P, Conti B (2007) Investigation of the degradation behaviour of poly (ethylene glycol-co-D,L-lactide) copolymer. Polym Degrad Stab 92:1660-1668

Elsawy MA, Kim K-H, Park J-W, Deep A (2017) Hydrolytic degradation of polylactic acid (PLA) and its composites. Renew Sustain Energy Rev 79:1346-1352

Engineer C, Parikh J, Raval A (2011) Review on hydrolytic degradation behavior of biodegradable polymers from controlled drug delivery system. Trends Biomater Artif Organs 25:79-85

Ensari N, Tutar H, Ekinci O, Ugur MB, Bayazit YA, Gokdogan C, Goksu N (2015) Effects of polylactic acid film on middle ear mucosa and cochlear function in Guinea pigs. Eur Arch Otorhinolaryngol 272:1091-1097

Feng L, Qi XR, Zhou XJ, Maitani Y, Wang SC, Jiang Y, Nagai T (2006) Pharmaceutical and immunological evaluation of a single-dose hepatitis B vaccine using PLGA microspheres. J Control Release 112:35-42

Feng T, Tian H, Xu C, Lin L, Xie Z, Lam MH-W, Liang H, Chen X (2014) Synergistic co-delivery of doxorubicin and paclitaxel by porous PLGA microspheres for pulmonary inhalation treatment. Eur J Pharm Biopharm 88:1086-1093

Frank A, Rath SK, Venkatraman SS (2005) Controlled release from bioerodible polymers: effect of drug type and polymer composition. J Control Release 102:333-344

Frede A, Neuhaus B, Klopfleisch R, Walker C, Buer J, Mueller W, Epple M, Westendorf AM (2016) Colonic gene silencing using siRNA-loaded calcium phosphate/PLGA nanoparticles ameliorates intestinal inflammation in vivo. J Control Release 222:86-96

Gajjar CR, King MW (2014) Degradation process. Resorbable fiberforming polymers for biotextile applications. Springer, New York

Galloway CJ, Dean GE, Marsh M, Rudnick G, Mellman I (1983) Acidification of macrophage and fibroblast endocytic vesicles in vitro. Proc Natl Acad Sci 80:3334-3338

Gao D-Y, Lin T-T, Sung Y-C, Liu YC, Chiang W-H, Chang C-C, Liu J-Y, Chen Y (2015) CXCR45-targeted lipid-coated PLGA nanoparticles deliver sorafenib and overcome acquired drug resistance in liver cancer. Biomaterials 67:194-203

Gaspar MC, Pais AA, Sousa JJ, Brillaut J, Olivier J-C (2019) Development of levofloxacin-loaded PLGA microspheres of suitable properties for sustained pulmonary release. Int $\mathrm{J}$ Pharm 556:117-124

Gentile P, Chiono V, Carmagnola I, Hatton P (2014) An overview of poly (lactic-co-glycolic) acid (PLGA)-based biomaterials for bone tissue engineering. Int J Mol Sci 15:3640-3659

Getts DR, Terry RL, Getts MT, Deffrasnes C, Müller M, van Vreden C, Ashhurst TM, Chami B, McCarthy D, Wu H (2014) Therapeutic inflammatory monocyte modulation using immune-modifying microparticles. Sci Transl Med 6:219ra7

Giannouli M, Karagkiozaki V, Pappa F, Moutsios I, Gravalidis C, Logothetidis S (2018) Fabrication of quercetin-loaded PLGA nanoparticles via electrohydrodynamic atomization for cardiovascular disease. Mater Today Proc 5:15998-16005

Giunchedi P, Conti B, Scalia S, Conte U (1998) In vitro degradation study of polyester microspheres by a new HPLC method for monomer release determination. J Control Release 56:53-62
Gomes dos Reis L, Lee W-H, Svolos M, Moir L, Jaber R, Windhab N, Young P, Traini D (2019) Nanotoxicologic effects of PLGA nanoparticles formulated with a cell-penetrating peptide: searching for a safe pDNA delivery system for the lungs. Pharmaceutics $11: 12$

Göpferich A (1996) Mechanisms of polymer degradation and erosion. Biomaterials 17:103-114

Gorrasi G, Pantani R (2013) Effect of PLA grades and morphologies on hydrolytic degradation at composting temperature: assessment of structural modification and kinetic parameters. Polym Degrad Stab 98:1006-1014

Goudarzi F, Asadi A, Afsharpour M, Jamadi RH (2018) In vitro characterization and evaluation of the cytotoxicity effects of nisin and nisin-loaded PLA-PEG-PLA nanoparticles on gastrointestinal (AGS and KYSE-30), hepatic (HepG2) and blood (K562) cancer cell lines. AAPS PharmSciTech 19:1554-1566

Gref R, Lück M, Quellec P, Marchand M, Dellacherie E, Harnisch S, Blunk T, Müller R (2000) 'Stealth' corona-core nanoparticles surface modified by polyethylene glycol (PEG): influences of the corona (PEG chain length and surface density) and of the core composition on phagocytic uptake and plasma protein adsorption. Colloids Surf B 18:301-313

Gustafson HH, Holt-Casper D, Grainger DW, Ghandehari H (2015) Nanoparticle uptake: the phagocyte problem. Nano Today 10:487-510

Gwak S-J, Yun Y, Kim KN, Ha Y (2016) Therapeutic use of 3 3 -[N$\left(\mathrm{N}^{\prime}, \mathrm{N}^{\prime}\right.$-dimethylaminoethane) carbamoyl] cholesterol-modified PLGA nanospheres as gene delivery vehicles for spinal cord injury. PLoS ONE 11:e0147389

Haggag YA, Matchett KB, Falconer RA, Isreb M, Jones J, Faheem A, McCarron P, El-Tanani M (2019) Novel ran-RCC1 inhibitory peptide-loaded nanoparticles have anti-cancer efficacy in vitro and in vivo. Cancers 11:222

Hamdy S, Haddadi A, Hung RW, Lavasanifar A (2011) Targeting dendritic cells with nano-particulate PLGA cancer vaccine formulations. Adv Drug Deliv Rev 63:943-955

Hanna LA, Basalious EB, ELGazayerly ON (2017) Respirable controlled release polymeric colloid (RCRPC) of bosentan for the management of pulmonary hypertension: in vitro aerosolization, histological examination and in vivo pulmonary absorption. Drug Delivery 24:188-198

Heo MB, Cho MY, Lim YT (2014) Polymer nanoparticles for enhanced immune response: combined delivery of tumor antigen and small interference RNA for immunosuppressive gene to dendritic cells. Acta Biomater 10:2169-2176

Hirota K, Doty AC, Ackermann R, Zhou J, Olsen KF, Feng MR, Wang Y, Choi S, Qu W, Schwendeman AS (2016) Characterizing release mechanisms of leuprolide acetate-loaded PLGA microspheres for IVIVC development I: in vitro evaluation. J Control Release 244:302-313

Hu C-MJ, Zhang L (2012) Nanoparticle-based combination therapy toward overcoming drug resistance in cancer. Biochem Pharmacol 83:1104-1111

Huang S-S, Li I-H, Po-da Hong M-KY (2014) Development of yersinia pestis F1 antigen-loaded microspheres vaccine against plague. Int J Nanomed 9:813

Hughes GA (2017) Nanostructure-mediated drug delivery. In: Balogh LP (ed) Nanomedicine in cancer. Pan Stanford Publishing, Singapore, pp 47-72

Jain AK, Das M, Swarnakar NK, Jain S (2011) Engineered PLGA nanoparticles: an emerging delivery tool in cancer therapeutics. Crit Rev Therap Drug Carr Syst 28:1-45

Jain AK, Massey A, Yusuf H, McDonald DM, McCarthy HO, Kett VL (2015) Development of polymeric-cationic peptide composite nanoparticles, a nanoparticle-in-nanoparticle system for controlled gene delivery. Int J Nanomed 10:7183 
Jain DS, Bajaj AN, Athawale RB, Shikhande SS, Pandey A, Goel PN, Gude RP, Patil S, Raut P (2016) Thermosensitive PLA based nanodispersion for targeting brain tumor via intranasal route. Mater Sci Eng, C 63:411-421

Jiang T, Singh B, Li H-S, Kim Y-K, Kang S-K, Nah J-W, Choi Y-J, Cho C-S (2014) Targeted oral delivery of BmpB vaccine using porous PLGA microparticles coated with $\mathrm{M}$ cell homing peptide-coupled chitosan. Biomaterials 35:2365-2373

Jose S, Sowmya S, Cinu T, Aleykutty N, Thomas S, Souto E (2014) Surface modified PLGA nanoparticles for brain targeting of Bacoside-A. Eur J Pharm Sci 63:29-35

Juturu V, Wu JC (2016) Microbial production of lactic acid: the latest development. Crit Rev Biotechnol 36:967-977

Kamaly N, Yameen B, Wu J, Farokhzad OC (2016) Degradable controlled-release polymers and polymeric nanoparticles: mechanisms of controlling drug release. Chem Rev 116:2602-2663

Kanchan V, Panda AK (2007) Interactions of antigen-loaded polylactide particles with macrophages and their correlation with the immune response. Biomaterials 28:5344-5357

Kapoor DN, Bhatia A, Kaur R, Sharma R, Kaur G, Dhawan S (2015) PLGA: a unique polymer for drug delivery. Therap Deliv 6:41-58

Kasturi SP, Skountzou I, Albrecht RA, Koutsonanos D, Hua T, Nakaya HI, Ravindran R, Stewart S, Alam M, Kwissa M (2011) Programming the magnitude and persistence of antibody responses with innate immunity. Nature 470:543

Kasyapi N, Mehta R, Bhowmick AK (2015) Raman and NMR spectroscopic studies on hydrolytic degradation of D,L-lactide- $\delta$ valerolactone-D,L-lactide copolymer. ACS Sustain Chem Eng 3:1381-1393

Kazzaz J, Singh M, Ugozzoli M, Chesko J, Soenawan E, O'hagan DT (2006) Encapsulation of the immune potentiators MPL and RC529 in PLG microparticles enhances their potency. J Control Release 110:566-573

Keles H, Naylor A, Clegg F, Sammon C (2015) Investigation of factors influencing the hydrolytic degradation of single PLGA microparticles. Polym Degrad Stab 119:228-241

Kim H, Lee J, Kim TH, Lee ES, Oh KT, Lee DH, Park E-S, Bae YH, Lee KC, Youn YS (2011) Albumin-coated porous hollow poly (lactic-co-glycolic acid) microparticles bound with palmitylacylated exendin-4 as a long-acting inhalation delivery system for the treatment of diabetes. Pharm Res 28:2008-2019

Kim HJ, Park JS, Yi SW, Oh HJ, Kim J-H, Park K-H (2018) Sequential transfection of RUNX2/SP7 and ATF4 coated onto dexamethasone-loaded nanospheresenhances osteogenesis. Sci Rep 8:1447

Koivistoinen OM, Kuivanen J, Barth D, Turkia H, Pitkänen J-P, Penttilä M, Richard P (2013) Glycolic acid production in the engineered yeasts Saccharomyces cerevisiae and Kluyveromyces lactis. Microb Cell Fact 12:82

Kolte A, Patil S, Lesimple P, Hanrahan JW, Misra A (2017) PEGylated composite nanoparticles of PLGA and polyethylenimine for safe and efficient delivery of pDNA to lungs. Int J Pharm 524:382-396

Kranz LM, Diken M, Haas H, Kreiter S, Loquai C, Reuter KC, Meng M, Fritz D, Vascotto F, Hefesha H (2016) Systemic RNA delivery to dendritic cells exploits antiviral defence for cancer immunotherapy. Nature 534:396

Kumari A, Yadav SK, Yadav SC (2010) Biodegradable polymeric nanoparticles based drug delivery systems. Colloids Surf B 75:1-18

KyungáKim Y (2016) Biomolecular strategies to modulate the macrophage response to implanted materials. J Mater Chem B 4:1600-1609

Lächelt U, Wagner E (2015) Nucleic acid therapeutics using polyplexes: a journey of 50 years (and beyond). Chem Rev 115:11043-11078. https://doi.org/10.1021/cr5006793
Lee BK, Yun Y, Park K (2016) PLA micro-and nano-particles. Adv Drug Deliv Rev 107:176-191

Leroy A, Ribeiro S, Grossiord C, Alves A, Vestberg RH, Salles V, Brunon C, Gritsch K, Grosgogeat B, Bayon Y (2017) FTIR microscopy contribution for comprehension of degradation mechanisms in PLA-based implantable medical devices. J Mater Sci Mater Med 28:87

Lewitus DY, Smith KL, Shain W, Bolikal D, Kohn J (2011) The fate of ultrafast degrading polymeric implants in the brain. Biomaterials 32:5543-5550

Liu R, Huang S-S, Wan Y-H, Ma G-H, Su Z-G (2006) Preparation of insulin-loaded PLA/PLGA microcapsules by a novel membrane emulsification method and its release in vitro. Colloids Surf B $51: 30-38$

Lü J-M, Wang X, Marin-Muller C, Wang H, Lin PH, Yao Q, Chen C (2009) Current advances in research and clinical applications of PLGA-based nanotechnology. Expert Rev Mol Diagn 9:325-341

Luten J, van Nostrum CF, De Smedt SC, Hennink WE (2008) Biodegradable polymers as non-viral carriers for plasmid DNA delivery. J Control Release 126:97-110

Luzardo-Alvarez A, Blarer N, Peter K, Romero JF, Reymond C, Corradin G, Gander B (2005) Biodegradable microspheres alone do not stimulate murine macrophages in vitro, but prolong antigen presentation by macrophages in vitro and stimulate a solid immune response in mice. J Control Release 109:62-76

Lyu S, Untereker D (2009) Degradability of polymers for implantable biomedical devices. Int J Mol Sci 10:4033-4065

Mahapatro A, Singh DK (2011) Biodegradable nanoparticles are excellent vehicle for site directed in vivo delivery of drugs and vaccines. J Nanobiotechnol 9:55

Makadia HK, Siegel SJ (2011) Poly lactic-co-glycolic acid (PLGA) as biodegradable controlled drug delivery carrier. Polymers 3:1377-1397

Mansor MH, Najberg M, Contini A, Alvarez-Lorenzo C, Garcion E, Jérôme C, Boury F (2018) Development of a non-toxic and nondenaturing formulation process for encapsulation of SDF-1 $\alpha$ into PLGA/PEG-PLGA nanoparticles to achieve sustained release. Eur J Pharm Biopharm 125:38-50

Marchany MD, Gardella JA Jr, Kuchera TJ (2015) Time of flight secondary ion mass spectrometry surface and in-depth study of degradation of nanosheet poly (l-lactic acid) films. Biointerphases 10:019010

Martins C, Sousa F, Araújo F, Sarmento B (2018) Functionalizing PLGA and PLGA derivatives for drug delivery and tissue regeneration applications. Adv Healthc Mater 7:1701035

Matta J, Maalouf R (2019) Delivery of siRNA therapeutics: PLGA nanoparticles approach. Front Biosci (Scholar edn) 11:56-74

Meng Q, Wang A, Hua H, Jiang Y, Wang Y, Mu H, Wu Z, Sun K (2018) Intranasal delivery of Huperzine A to the brain using lactoferrin-conjugated $\mathrm{N}$-trimethylated chitosan surface-modified PLGA nanoparticles for treatment of Alzheimer's disease. Int J Nanomed 13:705

Mir M, Ahmed N, ur Rehman A (2017) Recent applications of PLGA based nanostructures in drug delivery. Colloids Surf B 159:217-231

Mitchell MK, Hirt DE (2015) Degradation of PLA fibers at elevated temperature and humidity. Polym Eng Sci 55:1652-1660

Moghimi SM, Hunter AC, Murray JC (2001) Long-circulating and target-specific nanoparticles: theory to practice. Pharmacol Rev 53:283-318

Mohammadi-Samani S, Taghipour B (2015) PLGA micro and nanoparticles in delivery of peptides and proteins; problems and approaches. Pharm Dev Technol 20:385-393

Mok H, Park TG (2008) Direct plasmid DNA encapsulation within PLGA nanospheres by single oil-in-water emulsion method. Eur J Pharm Biopharm 68:105-111 
Müller AJ, Arnal ML, Lorenzo AT (2013) Crystallization in nanoconfined polymeric systems. In: Piorkowska E, Rutledge GC (eds) Handbook of polymer crystallization. Wiley, New York

Mundargi RC, Babu VR, Rangaswamy V, Patel P, Aminabhavi TM (2008) Nano/micro technologies for delivering macromolecular therapeutics using poly (D,L-lactide-co-glycolide) and its derivatives. J Control Release 125:193-209

Naldini L (2015) Gene therapy returns to centre stage. Nature 526:351

Newman KD, Elamanchili P, Kwon GS, Samuel J (2002) Uptake of poly (D,L-lactic-co-glycolic acid) microspheres by antigen-presenting cells in vivo. J Biomed Mater Res 60:480-486

Ni R, Muenster U, Zhao J, Zhang L, Becker-Pelster E-M, Rosenbruch M, Mao S (2017) Exploring polyvinylpyrrolidone in the engineering of large porous PLGA microparticles via single emulsion method with tunable sustained release in the lung: in vitro and in vivo characterization. J Control Release 249:11-22

Nishio H, Masumoto H, Sakamoto K, Yamazaki K, Ikeda T, Minatoya K (2018) MicroRNA-145-loaded poly (lactic-co-glycolic acid) nanoparticles attenuate venous intimal hyperplasia in a rabbit model. J Thorac Cardiovasc Surg. https://doi.org/10.1016/j.jtcvs .2018.08.115

Oyewumi MO, Kumar A, Cui Z (2010) Nano-microparticles as immune adjuvants: correlating particle sizes and the resultant immune responses. Expert Rev Vaccines 9:1095-1107

Pascual-Gil S, Simón-Yarza T, Garbayo E, Prosper F, Blanco-Prieto M (2015) Tracking the in vivo release of bioactive NRG from PLGA and PEG-PLGA microparticles in infarcted hearts. J Control Release 220:388-396

Patel BK, Parikh RH, Patel N (2018) Targeted delivery of mannosylated-PLGA nanoparticles of antiretroviral drug to brain. Int J Nanomed 13:97

Pinzon-Charry A, Ho C, Maxwell T, McGuckin M, Schmidt C, Furnival C, Pyke C, Lopez J (2007) Numerical and functional defects of blood dendritic cells in early-and late-stage breast cancer. $\mathrm{Br}$ J Cancer 97:1251

Priemel PA, Wang Y, Bohr A, Water JJ, Yang M, Mørck Nielsen H (2018) Poly (ethylene carbonate)-containing polylactic acid microparticles with rifampicin improve drug delivery to macrophages. J Pharm Pharmacol 70:1009-1021

Qian X, Long L, Shi Z, Liu C, Qiu M, Sheng J, Pu P, Yuan X, Ren Y, Kang C (2014) Star-branched amphiphilic PLA-b-PDMAEMA copolymers for co-delivery of miR-21 inhibitor and doxorubicin to treat glioma. Biomaterials 35:2322-2335

Ramot Y, Touitou D, Levin G, Ickowicz DE, Zada MH, Abbas R, Yankelson L, Domb AJ, Nyska A (2015) Interspecies differences in reaction to a biodegradable subcutaneous tissue filler: severe inflammatory granulomatous reaction in the Sinclair minipig. Toxicol Pathol 43:267-271

Ramot Y, Haim-Zada M, Domb AJ, Nyska A (2016) Biocompatibility and safety of PLA and its copolymers. Adv Drug Deliv Rev 107:153-162

Reis CP, Neufeld RJ, Veiga F (2017) Preparation of drug-loaded polymeric nanoparticles. In: Balogh LP (ed) Nanomedicine in cancer. Pan Stanford, Singapore, pp 197-240

Renukuntla J, Vadlapudi AD, Patel A, Boddu SH, Mitra AK (2013) Approaches for enhancing oral bioavailability of peptides and proteins. Int J Pharm 447:75-93

Rodriguez EJ, Marcos B, Huneault MA (2016) Hydrolysis of polylactide in aqueous media. J Appl Polym Sci. https://doi.org/10.1002/ app. 44152

Rong X, Yuan W, Lu Y, Mo X (2014) Safety evaluation of poly (lacticco-glycolic acid)/poly (lactic-acid) microspheres through intravitreal injection in rabbits. Int J Nanomed 9:3057

Ronneberger B, Kao WJ, Anderson JM, Kissel T (1996) In vivo biocompatibility study of ABA triblock copolymers consisting of
poly(L-lactic-co-glycolic acid) A blocks attached to central poly (oxyethylene) B blocks. J Biomed Mater Res 30:31-40

Rosas J, Hernandez R, Gascon A, Igartua M, Guzman F, Patarroyo M, Pedraz J (2001) Biodegradable PLGA microspheres as a delivery system for malaria synthetic peptide SPf66. Vaccine 19:4445-4451

Saini V, Jain V, Sudheesh M, Jaganathan K, Murthy P, Kohli D (2011) Comparison of humoral and cell-mediated immune responses to cationic PLGA microspheres containing recombinant hepatitis B antigen. Int J Pharm 408:50-57

Saini V, Verma AK, Kushwaha V, Joseph SK, Kalpna Murthy P, Kohli D (2014) Humoral and cell-mediated immune responses elicited by poly (D,L-lactide) adjuvanted filarial antigen molecules. Drug Deliv 21:233-241

Saluja SS, Hanlon DJ, Sharp FA, Hong E, Khalil D, Robinson E, Tigelaar R, Fahmy TM, Edelson RL (2014) Targeting human dendritic cells via DEC-205 using PLGA nanoparticles leads to enhanced cross-presentation of a melanoma-associated antigen. Int J Nanomed 9:5231

Salvador A, Igartua M, Hernández RM, Pedraz JL (2012) Combination of immune stimulating adjuvants with poly (lactide-co-glycolide) microspheres enhances the immune response of vaccines. Vaccine 30:589-596

Schlosser E, Mueller M, Fischer S, Basta S, Busch DH, Gander B, Groettrup M (2008) TLR ligands and antigen need to be coencapsulated into the same biodegradable microsphere for the generation of potent cytotoxic $\mathrm{T}$ lymphocyte responses. Vaccine 26:1626-1637

Seth A, Lee H, Cho MY, Park C, Korm S, Lee J-Y, Choi I, Lim YT, Hong KS (2017) Combining vasculature disrupting agent and toll-like receptor $7 / 8$ agonist for cancer therapy. Oncotarget 8:5371

Shao M, Zhu W, Lv X, Yang Q, Liu X, Xie Y, Tang P, Sun L (2018) encapsulation of chloroquine and doxorubicin by MPeg-Pla to enhance anticancer effects by lysosomes inhibition in ovarian cancer. Int J Nanomed 13:8231

Sharma S, Parmar A, Kori S, Sandhir R (2016) PLGA-based nanoparticles: a new paradigm in biomedical applications. TrAC, Trends Anal Chem 80:30-40

Shi S, Hickey AJ (2010) PLGA microparticles in respirable sizes enhance an in vitro $\mathrm{T}$ cell response to recombinant Mycobacterium tuberculosis antigen TB10.4-Ag85B. Pharm Res 27:350-360

Silva ATCR, Cardoso BCO, e Silva MESR, Freitas RFS, Sousa RG (2015) Synthesis, characterization, and study of PLGA copolymer in vitro degradation. J Biomater Nanobiotechnol 6:8

Sun T, Zhang YS, Pang B, Hyun DC, Yang M, Xia Y (2014) Engineered nanoparticles for drug delivery in cancer therapy. Angew Chem Int Ed 53:12320-12364

Tačić A, Ristić IS, Ilić D, Vesna N, Nikolić L, Snežana I-S (2017) Polymeric matrix systems for drug delivery, drug delivery approaches and nanosystems, vol 1. Apple Academic Press, Waretown, NJ, pp 95-131

Taha MA, Singh SR, Dennis VA (2012) Biodegradable PLGA85/15 nanoparticles as a delivery vehicle for Chlamydia trachomatis recombinant MOMP-187 peptide. Nanotechnology 23:325101

Tahara K, Sakai T, Yamamoto H, Takeuchi H, Hirashima N, Kawashima Y (2011) Improvements in transfection efficiency with chitosan modified poly (DL-lactide-co-glycolide) nanospheres prepared by the emulsion solvent diffusion method, for gene delivery. Chem Pharm Bull 59:298-301

Takami T, Murakami Y (2011) Development of PEG-PLA/PLGA microparticles for pulmonary drug delivery prepared by a novel emulsification technique assisted with amphiphilic block copolymers. Colloids Surf B 87:433-438 
Tam HH, Melo MB, Kang M, Pelet JM, Ruda VM, Foley MH, Hu JK, Kumari S, Crampton J, Baldeon AD (2016) Sustained antigen availability during germinal center initiation enhances antibody responses to vaccination. Proc Natl Acad Sci 113:E6639-E6648

Terry TL, Givens BE, Rodgers VG, Salem AK (2019) Tunable properties of poly-DL-lactide-monomethoxypolyethylene glycol porous microparticles for sustained release of polyethylenimine-DNA polyplexes. AAPS PharmSciTech 20:23

Tesfamariam B (2016) Bioresorbable vascular scaffolds: biodegradation, drug delivery and vascular remodeling. Pharmacol Res 107:163-171

Thanki K, Zeng X, Justesen S, Tejlmann S, Falkenberg E, Van Driessche E, Nielsen HM, Franzyk H, Foged C (2017) Engineering of small interfering RNA-loaded lipidoid-poly (DL-lactic-coglycolic acid) hybrid nanoparticles for highly efficient and safe gene silencing: a quality by design-based approach. Eur J Pharm Biopharm 120:22-33

Turek A, Kasperczyk J, Jelonek K, Borecka A, Janeczek H, Libera M, Gruchlik A, Dobrzyński P (2015) Thermal properties and morphology changes in degradation process of poly (L-lactideco-glycolide) matrices with risperidone. Acta Bioeng Biomech 17:11-20

Tyler B, Gullotti D, Mangraviti A, Utsuki T, Brem H (2016) Polylactic acid (PLA) controlled delivery carriers for biomedical applications. Adv Drug Deliv Rev 107:163-175

Tzeng SY, McHugh KJ, Behrens AM, Rose S, Sugarman JL, Ferber S, Langer R, Jaklenec A (2018) Stabilized single-injection inactivated polio vaccine elicits a strong neutralizing immune response. Proc Natl Acad Sci 115:E5269-E5278

von Burkersroda F, Schedl L, Göpferich A (2002) Why degradable polymers undergo surface erosion or bulk erosion. Biomaterials 23:4221-4231

Vroman I, Tighzert L (2009) Biodegradable polymers. Materials 2:307-344

Waeckerle-Men Y, Groettrup M (2005) PLGA microspheres for improved antigen delivery to dendritic cells as cellular vaccines. Adv Drug Deliv Rev 57:475-482

Wang N, Qiu J, Wu X (1998) Tailored polymeric materials for controlled delivery systems. ACS symposium series. ACS Publication, Washington

Widmer J, Thauvin C, Mottas I, Nguyen VN, Delie F, Allémann E, Bourquin C (2018) Polymer-based nanoparticles loaded with a TLR7 ligand to target the lymph node for immunostimulation. Int J Pharm 535:444-451

Wischke C, Zimmermann J, Wessinger B, Schendler A, Borchert H-H, Peters JH, Nesselhut T, Lorenzen DR (2009) Poly (I: C) coated PLGA microparticles induce dendritic cell maturation. Int $\mathrm{J}$ Pharm 365:61-68

Wong JKL, Mohseni R, Hamidieh AA, MacLaren RE, Habib N, Seifalian AM (2017) Will nanotechnology bring new hope for gene delivery? Trends Biotechnol 35:434-451. https://doi. org/10.1016/j.tibtech.2016.12.009

Xia H, Gao X, Gu G, Liu Z, Hu Q, Tu Y, Song Q, Yao L, Pang Z, Jiang $X$ (2012) Penetratin-functionalized PEG-PLA nanoparticles for brain drug delivery. Int J Pharm 436:840-850

Xiao Y, Shi K, Qu Y, Chu B, Qian Z (2019) Engineering nanoparticles for targeted delivery of nucleic acid therapeutics in tumor. Mol Therapy Methods Clin Dev 12:1-18. https://doi.org/10.1016/j. omtm.2018.09.002
Xiong Y, Yu Z, Lang Y, Hu J, Li H, Yan Y, Tu C, Yang T, Song Y, Duan H (2016) In vitro stress effect on degradation and drug release behaviors of basic fibroblast growth factor-poly (lacticco-glycolic-acid) microsphere. Drug Design Dev Therapy 10:431

Xu G, Zhang N (2009) Nanoparticles for gene delivery: a brief patent review. Recent Pat Drug Deliv Formul 3:125-136

Xu Y, Kim CS, Saylor DM, Koo D (2017) Polymer degradation and drug delivery in PLGA-based drug-polymer applications: a review of experiments and theories. J Biomed Mater Res B Appl Biomater 105:1692-1716

Xu Z, Wang D, Cheng Y, Yang M, Wu L-P (2018) Polyester based nanovehicles for siRNA delivery. Mater Sci Eng, C 92:1006-1015

Yan Y, Such GK, Johnston AP, Best JP, Caruso F (2012) Engineering particles for therapeutic delivery: prospects and challenges. ACS Nano 6:3663-3669

Yasar H, Biehl A, De Rossi C, Koch M, Murgia X, Loretz B, Lehr C-M (2018) Kinetics of mRNA delivery and protein translation in dendritic cells using lipid-coated PLGA nanoparticles. J Nanobiotechnol 16:72

Yoo JY, Kim JM, Seo KS, Jeong YK, Lee HB, Khang G (2005) Characterization of degradation behavior for PLGA in various $\mathrm{pH}$ condition by simple liquid chromatography method. Bio-Med Mater Eng 15:279-288

Yoo J-W, Chambers E, Mitragotri S (2010) Factors that control the circulation time of nanoparticles in blood: challenges, solutions and future prospects. Curr Pharm Des 16:2298-2307

Zhang Z, Tongchusak S, Mizukami Y, Kang YJ, Ioji T, Touma M, Reinhold B, Keskin DB, Reinherz EL, Sasada T (2011) Induction of anti-tumor cytotoxic T cell responses through PLGA-nanoparticle mediated antigen delivery. Biomaterials 32:3666-3678

Zhao Z-X, Gao S-Y, Wang J-C, Chen C-J, Zhao E-Y, Hou W-J, Feng Q, Gao L-Y, Liu X-Y, Zhang L-R (2012) Self-assembly nanomicelles based on cationic mPEG-PLA-b-polyarginine (R15) triblock copolymer for siRNA delivery. Biomaterials 33:6793-6807

Zhao W, Zhang C, Li B, Zhang X, Luo X, Zeng C, Li W, Gao M, Dong Y (2018) Lipid polymer hybrid nanomaterials for mRNA delivery. Cell Mol Bioeng 11:397-406

Zheng S, Li Luo RB, Liu Z, Xing J, Niu Y, Hu Y, Liu J, Wang D (2016) Evaluation of optimum conditions for pachyman encapsulated in poly (D,L-lactic acid) nanospheres by response surface methodology and results of a related in vitro study. Int J Nanomed 11:4891

Zhou S, Deng X (2002) In vitro degradation characteristics of poly-DLlactide-poly (ethylene glycol) microspheres containing human serum albumin. React Funct Polym 51:93-100

Zhu X, Xu Y, Solis LM, Tao W, Wang L, Behrens C, Xu X, Zhao L, Liu D, Wu J (2015) Long-circulating siRNA nanoparticles for validating prohibitin1-targeted non-small cell lung cancer treatment. Proc Natl Acad Sci 112:7779-7784

Zhu D, Tao W, Zhang H, Liu G, Wang T, Zhang L, Zeng X, Mei L (2016) Docetaxel (DTX)-loaded polydopamine-modified TPGSPLA nanoparticles as a targeted drug delivery system for the treatment of liver cancer. Acta Biomater 30:144-154

Zolnik BS, Burgess DJ (2007) Effect of acidic pH on PLGA microsphere degradation and release. J Control Release 122:338-344

Publisher's Note Springer Nature remains neutral with regard to jurisdictional claims in published maps and institutional affiliations. 